\title{
Predictive potentials of 8 muscle strength actions, KOOS-pain, and Örebro-psychosocial difficulties on self-reported activities-of-daily-life function in patients with knee osteoarthritis: an exploratory regression-based cross-sectional study
}

Kjartan Vårbakken ( $\sim$ kjartanv@ntnu.no )

Norwegian University of Science and Technology

Håvard Lorås

Nord University

Kjell Nilsson

Umeå University

Monika Engdal

St Olav's University Hospital

Ann-Katrin Stensdotter

Norwegian University of Science and Technology

\section{Research Article}

Keywords: Osteoarthritis, Knee, Cross-sectional Studies, Muscle Strength Dynamometer, Psychology, Sociology, Activity of Daily Living, Chronic Pain, Multivariable Analysis, Association

Posted Date: December 1st, 2020

DOl: https://doi.org/10.21203/rs.3.rs-114877/v1

License: (c) (i) This work is licensed under a Creative Commons Attribution 4.0 International License.

Read Full License 
1 Predictive potentials of 8 muscle strength actions, KOOS-pain, and

2 Örebro-psychosocial difficulties on self-reported activities-of-daily-life

3 function in patients with knee osteoarthritis: an exploratory

4 regression-based cross-sectional study

$5 \quad$ Vårbakken $\mathrm{K}^{1^{*}}$, Lorås $\mathrm{H}^{2}$, Nilsson $\mathrm{KG}^{3}$, Engdal $\mathrm{M}^{4}$, Stensdotter $\mathrm{AK}^{1}$

$6 \quad{ }^{1}$ Norwegian University of Science and Technology, Department of Neuromedicine and

7 Movement Science, Trondheim, Norway, ${ }^{2}$ Nord University, Department of Physical

8 Education and Sport Science, Levanger, Norway, ${ }^{3}$ Umea University, Surgical and

9 Perioperative Sciences, Umea, Sweden, ${ }^{4}$ Trondheim University Hospital, Department of

10 Physiotherapy, Clinic of Clinical Services, Trondheim, Norway

11

*Corresponding author

13 Mr. Kjartan Vårbakken

14 Faculty of Medicine and Health Sciences

15 NTNU, Health og Social building

7491 Trondheim, Norway

E-mail: kjartanv@,ntnu.no

Abstract

Background

21 The aim of the study was to explore the relative predictive potentials of a discriminative and comprehensive set of lower-limb muscle strength factors onto self-reported physicalactivities-of-daily-life-function (SR-ADL-function) in patients with knee osteoarthritis 
24 (KOA), when adjusting for prior known strong prospective predictors in a statistical model

which covers the functional domains of the International Classification of Function,

Disability, and Health (ICF).

\section{Methods}

The design was exploratory, patient-only, cross-sectional, and multivariable regression-based, rotating 8 strength-variables onto a hierarchical model. The setting was an Osteoarthritisschool in a secondary-care hospital in Norway. The participants were 28 Caucasian patients with mild-to-moderate symptomatic and radiographic KOA (mean age 61; 64\% women) referred by general physicians to an osteoarthritis-school. Excluded patients had trauma to the lower limbs, BMI >35, and age beyond 45 to 70 . The dependent/outcome variable was SRADL-function (Knee Injury and Osteoarthritis Outcome Score [KOOS-ADL]). The known predictors were prior documented discriminative KOOS-Pain and psychosocial difficulties (Örebro Musculoskeletal Pain Questionnaire), together with 8 candidate predictor lower-limb muscle-strength actions (Biodex and Commander II dynamometer recorded).

\section{Results}

Mutually adjusted for pain and psychosocial difficulties $\left(\mathrm{R}^{2}=0.71\right)$, the predicting musclestrength actions explained the following unique variances in SR-ADL-function: hip external rotation $7.6 \%(p<0.010)$, ankle eversion $4.0 \%(p=0.050)$, hip internal rotation $3.8 \%(p=0.060)$, ankle inversion $3.6 \%(\mathrm{p}=0.066)$. The remaining 4 muscle-strength actions explained from $2.0 \%$ to $1.2 \%$ ( $>0.099)$, where knee extensor strength explained the least unique variance. Flipped, the current three best potential prediction models explained the following substantial proportions of variance in SR-ADL-function: 1) KOOS-pain, 66\%; 2) KOOS-pain and Örebro psychosocial difficulties, 71\%; and 3) KOOS-pain, Örebro psychosocial difficulties, and hip 
60

external rotation strength, $78 \%$.

\section{Conclusions}

Adjusted for pain and psychosocial difficulties, hip rotations and ankle eversion-inversion strength indicate substantial cross-sectional potentials for predicting SR-ADL-function for patients with KOA aged 45 to 70 in primary/hospital health-care. Relevant for future prevention and prediction/treatment studies, however, we suggest clinical researchers to consider the current muscle-strength actions together with the even stronger biopsychosocial predictors KOOS-pain and Örebro psychosocial difficulties for future ICF domain-covering models of SR-ADL. Future confirmative studies are needed to refute or generalize these pioneering exploratory conclusions.

Keywords: Osteoarthritis, Knee; Cross-sectional Studies; Muscle Strength Dynamometer; Psychology; Sociology; Activity of Daily Living, Chronic Pain; Multivariable Analysis; Association. 4 65 66

\section{Background}

Osteoarthritis (OA) is responsible for substantial health and social costs, directly and indirectly through work impairment and early retirement (3-6). OA is the second most prevalent condition of all musculoskeletal and rheumatic diseases $(7,8)$. Herein, knee OA (KOA) is reliably diagnosed by the criteria of the European League Against Rheumatism (EULAR) in primary care (9), and by the criteria of the American College of Rheumatology [ACR](10) in hospital care (9). The KOA incidence is high, about 240 per 100000 person- 
74 years in adults, or more than 2.5 times than of hip OA (11). KOA is the main contributor to activity limitations in persons older than 45 years $(7,8)$. Self-reported physical activity in daily life functional [SR-ADL-function] limitations (i.e. perceived difficulties) for these patients are related to muscle strength deficits (12).

Strength is defined as the maximum force or torque a muscle or muscle-group can produce given a specific predetermined velocity (13-15). Therein, task-specific conditions, such as the speed and type of contraction and the length of the muscle during contraction, all codetermine the torque generated $(14,16,17)$. The American College of Sports Medicine (ACSM) exemplifies strength as a 1 repetition maximum (1RM) squat (16). Moderate to large(18) deficits in muscle strength are frequent in patients with $\operatorname{KOA}(19,20)$. Recent, metaanalyses demonstrate hip rotations and knee extensor muscle strength to be on average 20 $40 \%$ lower compared with healthy age-matched controls $(19,20)$. Moreover, meta-analytic evidence documents knee extensor strength deficit to be a risk factor for radiographic progression (21) and the development of KOA (22). Interestingly, knee extensor muscle strengthening alone have demonstrated small to large (18) improvement on pain and SRADL-functional limitations compared to wait-and-see controls in meta-analyzed randomized trials [RCTs] (23-25). Even more interesting, subgroup-data of a meta-analysis (26) indicated the largest treatment effects on pain and SR-ADL function of so-called hip abductor and knee extension strength exercising compared to knee extension strength exercising alone in patients with KOA in a potentially mechanism-triggering (2) RCT (27). However, the importance of muscle strength deficits in various joint—-strength directions between patients and healthy controls shown in a recent meta-analysis (19) has yet to be evaluated in clinical trials. Adding to the strength discrimination knowledge, we just presented the apparently first study (28) to compare a comprehensive list of lower-limb strength actions between patients with KOA and 
99 healthy controls. The most substantive relative strength deficits were indicated for the hip

100 rotator muscles, closely followed by that of the ankle invertor-evertors, and the knee extensor

101 muscles.

102

103 Biopsychosocially evaluated, in the same study [i.e., same sample, different data] (29), we

104 quantified the discrimination of 27 KOA measures as between-group differences using a 105 standardized effect size (18). Among the ICF (International Classification of Functioning,

106 Disability and Health) related measures (29), we found the most substantial discrimination on

107 KOA-specific SR-ADL function, KOOS-pain, and psychosocial difficulties. Indeed, the

108 psychosocial difficulties factor has prospectively predicted the prime KOA-outcome SR-ADL

109 function in patients with non-acute musculoskeletal pain (30). In a systematic review of

110 prospective studies (31), the same primary KOA-outcome is found importantly predicted by

111 pain in patients with KOA.

112

113 Summed, the evidence above points towards various muscle strength actions as potential

114 predictors for easing SR-ADL function in patients with KOA. That is important as SR-ADL

115 function is the most important functional measure, because its activities are fundamental to

116 higher level functions (f. ex. Recreation/Sport) and necessary for independent living, its

117 construct is not highly variable as the more psychology taxing knee-related quality-of-life

118 (KR-QoL), and it is the recommended functional measure in a consensus set given by

119 patients, scientists and clinicians (32). Various muscle strengths are important predictors or

120 causes of SR-ADL function according to systematic reviews of RCTs $(19,23)$. Further,

121 muscle strength is necessary for full ADL-performance, whereas even vigorous physical ADL

122 performance is insufficient for maintaining proper strength of supportive muscles (33-35).

123 However, according to systematic reviews $(21,36)$ neither existing cross-sectional relational 
124 nor prospective studies has yet systematically explored the predictive potential/cross sectional

125 relationships of the most discriminative joint-strength actions (28) towards the primary

126 KOA-outcome SR-ADL function. Especially not so when adjusted for prior known important

127 predictive variables. The current knowledge-gap limits the understanding of which muscle

128 strength actions have the largest potential for predicting SR-ADL function for these patients.

129 This gap needs closing, especially since prognosis-enhancing short and targeted strength

130 programs show better achievability and effectiveness then long-durable and comprehensive

131 ones $(26,37)$.

132

133 Thus, the purpose of the current study was to explore (38) the relative adjusted cross-sectional

134 predictive potential (i.e. independent relations) of known discriminative strength actions on

135 SR-ADL function in patients with KOA. Adjusted; that is, if each strength action is to be

136 regressed on the outcome in a hierarchical model together with prior known strong predictors.

137 The overall purpose was to indicate which joint-strength actions may have the highest cross-

138 sectional potentials for inclusion in multivariable and biopsychosocial ICF-domain covering

139 management models for future confirmative and prospective prediction studies of the SR-

140 ADL-outcome for patients with KOA.

141

142 The current study was exploratory because it had several objectives (i.e. to find the adjusted

143 relative magnitude of the predictive potentials of various muscle-groups); that is, it did not

144 have a single key hypothesis $(38,39)$. The latter is the case in confirmatory studies.

145 Exploratory studies lay the wide-scoped fundaments for future confirmatory studies. 
147

148

149

150

151

152

153

154

155

156

157

158

159

160

161

162

163

164

165

166

167

168

169 questionnaires took about 40 minutes and the physical functional test protocol 2.7 hours.

\section{Methods}

The current paper presents data from a larger study, Function with knee osteoarthritis [FUNKART] $(28,40)$.

\section{Design and recruitment}

The current study was exploratory, cross-sectional, case-only, and multivariable relational. Based on statistical rules of thumb regarding the number of cases per predictor variable (31, $41,42)$ and the assumption about no adjustment needed for multiple comparisons in exploratory studies $(38,39,43-46)$, we initially aimed for 30 participants (cf. Statistics analysis). We recruited individuals with KOA referred by general physicians (GPs) to private physiotherapy clinics and to an OA-school at a university hospital in Norway from November 2016 to December 2017.

\section{Ethics approval and informed consent}

This study was approved by the Regional Committees for Medical and Health Research Ethics, Norway (2016/984, the Regional Ethics Committee North) and performed according to the Helsinki Declaration, and Norwegian regulations. All participants received oral and written information and signed an informed consent form before entering the study.

Data were collected within a period of approximately two weeks through questionnaires and functional tests in the lab. The questionnaires were e-mailed as web-surveys together with the informed consent forms via the Infopad system (47). The main study was extensive as the 
172 The inclusion criteria for patients were having KOA in the tibiofemoral joint in one or both 173 knees diagnosed clinically (by GPs) and radiologically [Kellgren-Lawrence grade (K/L-grade)

\section{Participants eligibility} I-IV] (48), main problem of pain and limited physical function related to the knee(s), be symptomatic for $>3$ months and daily in the last month, understand Norwegian, and be within 45-70 years old. Both genders were included. The upper age-limit was sat in a prior case-vshealthy control comparison study on the same sample [to prevent possible confounding, $\mathrm{cf}$. $(28,40)]$

The exclusion criteria were surgery to a lower extremity $<3$ years ago, prior lower limb fractures, generalized pain $(49,50)$, pain from the spine, hips, or ankles competing with that from the knee, body mass index $(\mathrm{BMI})>35$ (for reliable optokinematic recordings $(51)$ in the larger study, data not presented here), and medical diagnoses other than KOA with clear negative influence on physical performance and pain.

\section{Measurements}

\section{Strength candidate predictors}

For a full description of the 12-variable strength-testing procedure, cf. our discriminative strength study (28). Here we present procedures for the 8 strength actions in the current study. Before strength testing, the participants warmed up by several performance tests included in the larger study of the same sample (40). The 6-minute walk test (6MWT), a timed 10-step up-and-down stair-climb test [cf. ref.(40) for results], and a set of 15 repetitions at low-tomoderate load on each specific exercise, were performed. Strength or concentric peak torque were recorded at $60^{\circ} / \mathrm{s}$ by the isokinetic mode applying the reliable Biodex ${ }^{\circledR}$ System 4 Dynamometer [Biodex Medical Systems, NY, USA] $(52,53)$. With the participants sitting, 
196 we sequentially tested strength with the back rest tilted $70^{\circ}$ off the horizontal line in the

197 following order: knee flexion and extension, hip internal and external rotation, ankle inversion

198 and eversion, and ankle plantar flexion. These positions and setups were according to the

199 Biodex manual (54), except for the hip rotation tests that were performed according to Baldon

200 et al. (55). Further, with the participants positioned supine on a therapy bench, we tested

201 isometric hip abduction strength with the hips in a neutral ab-adducted position, applying a

202 hand-held muscle tester dynamometer (HHD) [type specified below] according to Thorborg et

203 al. (56), except before testing, the pelvis was additionally secured bilaterally against inferior

204 and lateral displacement (57). The supine isometric abduction test was included instead of the

205 side-lying Biodex test because we have experienced that weak patients may be unable to lift

206 the weight of the resistance arm and their leg in the latter (causing floor effects).

207

208 We applied five consecutive maximum strength tests by the Biodex system and three repeated 209 trials by the belt-fixed HHD. Oral encouragements were applied according to principles in 210 Thorborg (56). For the knee tests, the Biodex system's "passive isokinetic mode" was chosen, 211 to better accommodate eccentric performance (eccentric data not reported here). Accordingly, 212 fully passive recordings were taken to correct for gravity (see Data processing). The other

213 tests by the Biodex system, we corrected for gravity by its software. The Biodex system was 214 calibrated before each session according to the manual (54). Muscle strength measurements 215 with an isokinetic dynamometer have shown excellent test-retest reliability (ICC 0.93) in 216 patients with KOA (58). The HHD (Commander II Muscle Tester, JTech Medical Industries, 217 USA) is certified by the National Institute of Standards and Technology (NIST) standards. 218 The HHD is self-calibrating and was compared daily to an identical reserve-HHD, and both 219 were weekly compared to traceable Olympic Competition Weights (59) [Eleiko, Halmstad, 220 Sweden]. The team of testers trained about 40 hours to execute the complete strength protocol 
within 1.5 hours.

The chosen outcome variable was KOOS-Activities in Daily Life (ADL) function, from the self-reported (SR) Knee Injury and Osteoarthritis Outcome Score (KOOS) questionnaire (6062). The KOOS-ADL was chosen (over the Western Ontario and McMaster Universities Arthritis Index Physical Function [WOMAC-PF]) due to being open access (63), knee specific, electronically available [at non-profit costs in a system (47), or at no-cost (63)], and showing adequate measurement properties $(63,64)$. The KOOS is scaled $0-100$, worst to best, the highest score expressing the best ADL function. KOOS asks for the period "last week".

The initially considered candidates as non-strength predictor variables (or covariables or adjusting variables) were as follows: KOOS-pain [0-100, worst to best] (60-62), psychosocial difficulties [Örebro Musculoskeletal Pain Screening Questionnaire 10-items (OMSPQ-10), 1100 , best to worst] (65), body mass index (BMI, $\left.\mathrm{kg} / \mathrm{m}^{2}\right)$, average pain last week [Numeric Pain Rating Scale (NPRS), 0-10, best to worst] (66), fear of movement/re-injury [Tampa 237 Scale of Kinesiophobia (TSK-13), 13-52 point, best to worst] (67), age (years), time in 238 activity of moderate intensity (AX3, a 3-axis logging accelerometer, Axivity Ltd, Newcastle, $239 \mathrm{UK}$, minutes/week) $(40,68,69)$, endurance or long-term walking capability [6-minute walk 240 test (6MWT); distance, m] (70), general health quality of life [The European Health Interview 241 Survey-Quality of Life 8-item index (EUROHIS-QoL), 8-40 points, worst to best] (71), and 242 pain duration [number of months] (31). Note that KOOS-pain (60-62) at its highest score expresses the best KOA-pain-

244 function (least painful), whereas Örebro psychosocial difficulties (65) is scaled in the intuitive 245 direction. Örebro (65) captures work and psychosocial factors, where the original version 
identify yellow flags and risk of work disability due to pain $(72,73)$ and has satisfactory psychometric properties and predictive ability (74). The chosen short version (65) has improved clinical utility and similar psychometric properties in a mixed musculoskeletal pain

249 population.

251 After the questionnaires, in the laboratory the week thereafter, we registered personal or 252 demographic characteristics, clinical factors, and degree of radiographic KOA [from 253 radiology reports] (48) [cf. Results, Table 1]. In the second half of the lab-session, we 254 measured peak strength. At the end of the lab session, an accelerometer sensor was applied on 255 the anterior left thigh $(69,75)$ and worn for all hours during one week, before it was returned 256 by conventional mail.

\section{Confounding and sensitivity analysis variables}

259 Based on systematic reviews of prospective predictors in cohort-studies (31), causal variables 260 in therapeutic RCTs $(25,26,76,77)$, and our study of case-vs-control discriminative 261 indications (40), we considered the following variables for a confounding and sensitivity 262 analysis (Cf. Statistics analysis): KOOS-pain, psychosocial difficulties, age, fear of 263 movement/re-injury, time in activity of moderate intensity, and endurance.

\section{Data processing}

266 For concentric knee extensor strength, the passive torques were added to the active ones to 267 correct for the limb's own torque, whereas for knee flexion the passive torques were 268 subtracted. Maximum knee strength at the $30^{\circ}$ knee flexed position $\left(0^{\circ}=\right.$ straight knee $)$ was 269 reported. The isokinetic mode with software gravity correction was used for the remaining isokinetic tests. In the Biodex-dynamometer tests, the "cushion -function" was set to "hard" 
271 and the signal windowing to $80 \%$. For all tests, strength was taken as "best of" and

272 normalized to body weight (i.e. divided by mass), thus we report $\mathrm{Nm} / \mathrm{kg}$.

Statistical analysis

275 Our sample size calculation assumed that no adjustments for multiple comparisons were

276 needed in the current exploratory study according to several reputative statisticians $(38,39$,

277 43-46). All power analysis was performed in the recognized(41) freeware G*Power version

278 3.1.9.1 (78-80). Bivariate correlations were performed as part of the statistical analysis, where

279 methods and results and discussion are placed in an e-appendix (to improve readability).

281 The a priori sample size calculation for the multiple regression analysis was performed for a

282 t-test-based linear regression fixed model with a single continuous coefficient per predictor.

283 Therein, the input factors were two tails, effect size $f^{2} 0.35$ [i.e. a large effect (81)], $\alpha$ error

284 probability 0.05 , power ( $1-\beta$ error probability) 0.80 , and 3 predictors. The sample required 285 was then 25 cases. Thus, we aimed for 29 participants altogether.

287 Analytically, case numbers vs. value plots showed no missing data from lab tests or 288 questionnaires. Requirements of independence and representativeness were assumed met due 289 to the design. The inspection of variables, histograms, box plots, Shapiro-Wilk tests, and 290 Normal Q-Q plots, indicated normal distribution, no obvious outliers, and roughly constant 291 variance. Moreover, the assumption of normal distributed residuals was bypassed by the biascorrected bootstrap inference included in SPSS (IBM, NY, USA, v.25) for both the Pearson's correlation analysis and the multiple regression analysis $(41,82)$. Yet further, the bivariate

294 correlation matrix showed moderate correlation $[\mathrm{r}<0.70](83)$ between the chosen non295 strength candidate predictor variables (cf. Results in e-appendix). Candidate non-strength 
296 predictors that showed high co-linearity with most candidate strength predictors were excluded before the selecting process assuming they contribute little independent information [e.g. BMI] (84).

Even further, we analyzed the bivariate correlation matrix for patterns, including the variables for a planned multivariable model for the presumed predictors $X_{1}, X_{2}$, and $X_{3 \mathrm{i}}$ and the outcome $Y$ (e-appendix). The standard generic linear multivariable model/equation (Eq. 1) was as follows:

$$
\widehat{Y}=\mathrm{b}_{0}+\mathrm{b}_{1} X_{1}+\mathrm{b}_{2} X_{2}+\mathrm{b}_{3} X_{3 \mathrm{i}}
$$

, where $\hat{Y}$ is the estimated (mean) outcome of SR-ADL function, $\mathrm{b}_{0}$ the intercept or estimated SR-ADL-level when each predictor is zero (nonsensical in this case), $b_{1}, b_{2}$, and $b_{3}$ the slope of the lines (or weight or effect estimates or regression coefficients) of the predictor or explanatory variables $X_{1}, X_{2}, X_{3 \mathrm{i}}$, where the ${ }_{\mathrm{i}}$ denotes the $\mathrm{i}$ 'th joint-strength action variable (8 in total).

\section{The selection of the first and second candidate non-strength predictor variables $\left(X_{1}, X_{2}\right)$ was} based on the following criteria: (i) bivariate current-study findings of candidates (for $X_{1}$ and $X_{2}$ ) should have significant moderate-to-high correlation with the outcome variable and lowto-moderate correlation with the strength variables $\left(X_{3 \mathrm{i}}\right)$, (ii) covering the psychosocial aspect of ICF with proven predictive capabilities (31), and (iii) documented clear case-vs-control discrimination in the prior study (40). The strength actions shown to be discriminative (on the most affected leg) in another of our case-vs-healthy control studies (28) on the same sample, were evaluated as $X_{3 \mathrm{i}}$ (cf. Results, Table 1), but therein we also included hip abduction due to 
321 prior proven causal/trial effects $(26,85)$. For choosing the first and second candidate predictors, we also considered a confounding analysis (cf. $2^{\text {nd }}$ paragraph below).

After the bivariate analysis (e-appendix), we explored the data in a hierarchical regression analysis for "best" non-strength candidates for $X_{1}$ and $X_{2}$. First, candidates were regressed one-by-one (onto SR-ADL) according to their bivariate correlation magnitude, then in various hierarchical orders. The criterium for the "best" two-predictor model was maximum explained variance, $\mathrm{R}^{2}$, while including a biopsychosocial construct. Because of the sample size vs number of allowed predictors constraint, we thereafter rotated (as in a Colt-gun magazine) each strength variable onto (and off) the best fitting two-variable model. The results were then rated and tabulated to fulfill the purpose.

333 Our confounding analysis is explained further in the e-appendix. In short, based on background knowledge of prospective predictors (31), causal (RCT manipulated treatment) variables (37), cross-sectionally case-controlled discriminative variables $(1,20)$, but also (based) on the size and significance of the bivariate and exploratory multivarible relationships in the current study, we created a causal diagram (directed acyclic graph) applying the DAGitty freeware [DAGitty.net] $(86,87)$. According to a causal diagram analysis $(87-90)$ the current study's potential confounders of the total effect of strength came out as KOOS-pain

340 and age (Figure 1). However, in the current chosen primary analysis, in compliance with our 341 selection criteria and current power constraint, we decided to adjust for KOOS-pain and 342 psychosocial difficulties. BMI was not included in the model because the strength results 343 were normalized to body weight (91), BMI showed no discrimination in the prior study (1), 344 and it showed moderate-high correlation with all candidate strength predictors in the current 345 correlation matrix (e-appendix). Figure 1 shows the diagram of the causal modeling of the 
346 total effect of strength on SR-ADL with the influence of the potential confounder variables

347 (arrow-connected pink nodes) and the implied or assumed non-associated variables

348 (unconnected gray nodes).

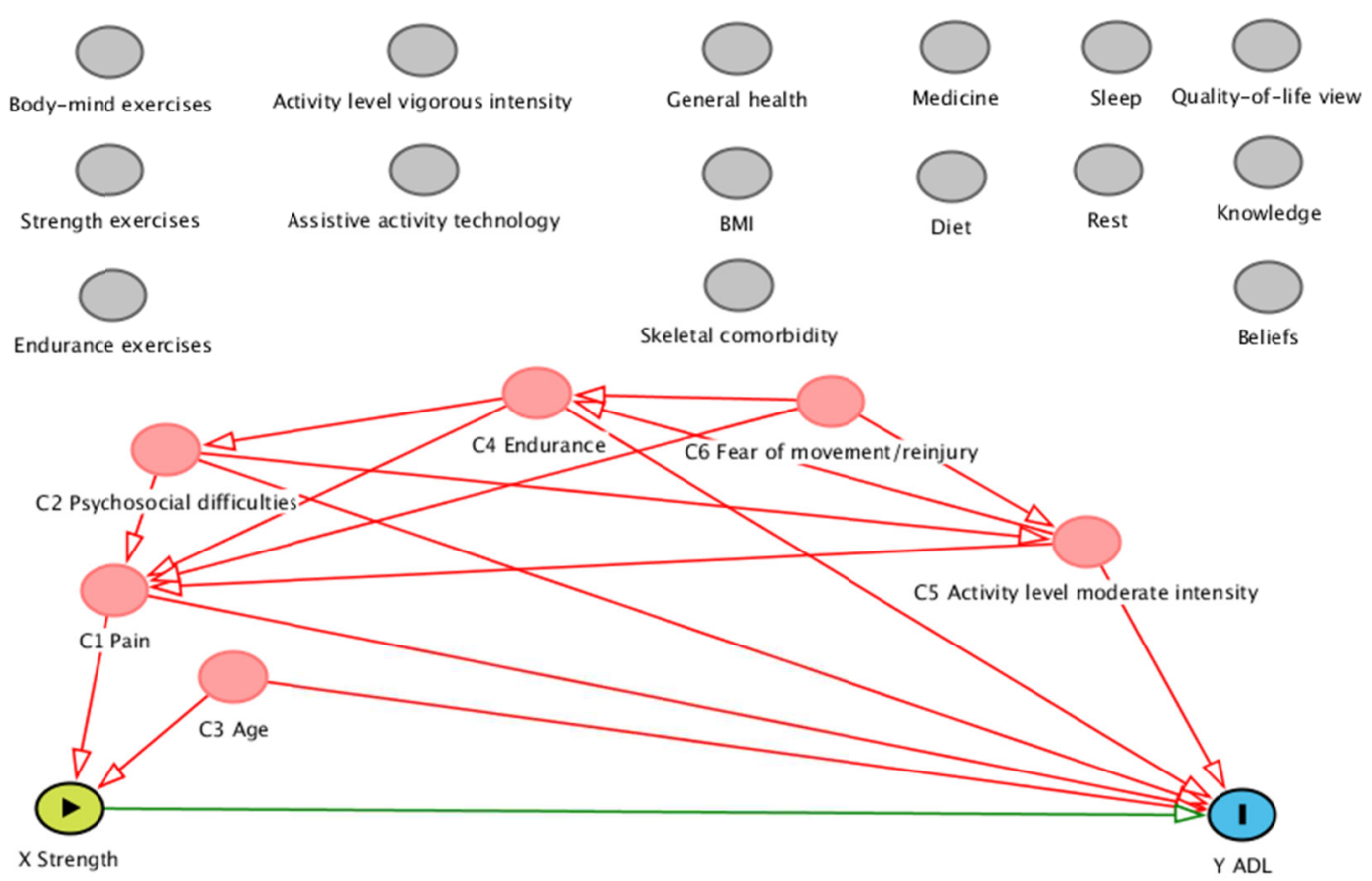

Figure 1. Modeling the total effect (green arrow) of the assumed focal predictor Strength (green play-button) on the putative outcome Activity of daily life (blue stop-button), together with the potential confounders (pink buttons, C1-C6) with their putative confounding or causal effects on the focal predictor and outcome (pink arrows) to be adjusted for in the multiple regression model. The gray buttons were ruled out of the main model basied on case vs control non-discriminative characteristics in prior studies $(1,2)$ and the inclusion criteria in the current study (C4 skeletal comorbidity).

353 Finally, having ran the best-fitting models, collinearity diagnostics statistics showed no

354 eigenvalues $<1$ nor condition indexes $>15$; i.e., data met the non-multicollinearity

355 assumption (41). Thus, we inferred that the assumptions of the bivariate correlation and the 356 multiple regression models were met. 


\section{Sensitivity analysis}

359 In a sensitivity analysis (92) [e-appendix], we checked the robustness of the models by

360 replacing psychosocial difficulties with age in accordance with the result of the current causal

361 diagram confounder analysis (the sensitivity equation/model is not shown). The sensitivity

362 analysis was compared with that of the generic model (Eq. 1) which was (partially) specified

363 for the main analysis as follows (Eq. 2):

364

$$
\widehat{A D L}=\mathrm{b}_{0}+\mathrm{b}_{1} \text { KOOS-pain }+\mathrm{b}_{2} \text { psychosocial difficulties }+\mathrm{b}_{3 \mathrm{i}} \text { strength }
$$

, where $\widehat{A D L}$ is the estimated (mean) outcome of KOOS-SR-ADL function, $\mathrm{b}_{0}$ the intercept or estimated SR-ADL function when each predictor is zero (not sensical in this case), $b_{1}, b_{2}$, and $b_{3}$ the slope of the lines/relational weights/beta coefficients of the predictor variables KOOSpain, psychosocial difficulties, and strength, respectively. We repeated the main analysis for all joint-strength actions rotated into the two-predictor model (Eq. 2).

All bivariate (e-appendix) and multivariable statistical tests were run in SPSS (IBM, NY, USA, v.25). Alpha was set to 0.05 for all tests as no adjustments were assumed needed in an exploratory study $(38,39,43-46)$. No multiple imputation was performed for the single dropout participant. 
381 participate demotivated by long traveling distances $(n=3)$, not interested $(n=4)$, afraid of strength

382 testing $(\mathrm{n}=2)$, and too time-consuming $(\mathrm{n}=1)$. One participant answered the questionnaire but

383 withdrew from the study before the lab-test due to a flare-up at home and thus was excluded from

384 the analysis. Two participants were recruited in municipality physiotherapy clinics without

385 information on those who declined. Herein, additional five individuals volunteered but were

386 screened per telephone as to not be qualified for participation due to old age $(n=3)$, BMI $(n=1)$,

387 and an unstable heart $(\mathrm{n}=1)$, and were therefore not included. Thus, we included 28 patients.

390 The patient-group was middle-aged with mainly graduate level of education $(n=14,50 \%)$. The

391 group had slightly more females (64\%) than men, long-term knee pain (on average 10 years),

392 and mainly small-to-moderate symptomatic and radiographic KOA. Further, it was

393 overweight on average [mean BMI of 28, BMI classifying overweight is 25 to $30(93,94)]$.

394 Table 1 shows the group's demographic and clinical characteristics. 
411 Table 1. Personal and health characteristics of patients with KOA.

\begin{tabular}{|c|c|c|c|}
\hline ICF & Variables & $\begin{array}{c}\text { Cases } \\
(\mathrm{n}=\mathbf{2 8})\end{array}$ & \\
\hline \multirow{11}{*}{ 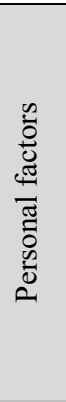 } & Female, n (\%) & $18(64)$ & \\
\hline & Age, yrs, M (SD) & $61.7(6.4)$ & \\
\hline & Height, m, M (SD) & $1.72(0.10)$ & \\
\hline & Weight, kg, M (SD) & $82.9(12.7)$ & \\
\hline & BMI, $\mathrm{kg} / \mathrm{m}^{2}, \mathrm{M}$ (SD) & $28.0(4.1)$ & \\
\hline & Education, $\mathrm{n}(\%)$ & & \\
\hline & secondary school (10 yrs) & $1(4)$ & \\
\hline & high school (13 yrs) & $6(21)$ & \\
\hline & graduate (16 yrs) & $14(50)$ & \\
\hline & post graduate $(18 \mathrm{yrs}+)$ & $7(25)$ & \\
\hline & Dominant leg (right, left, n) & 26,2 & \\
\hline \multirow{27}{*}{ 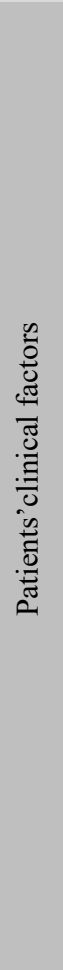 } & Yrs since diagnosis, $M(\mathrm{SD})$ & $10.2(8.6)$ & \\
\hline & Duration knee pain, mo, M (SD) & $132.7(101.6)$ & \\
\hline & Pain last wk NRS, M (SD) & $4.4(2.3)$ & \\
\hline & Affected knee (n, \%) & & \\
\hline & One & $14(50)$ & \\
\hline & Both & $14(50)$ & \\
\hline & Pain medication (n, \%) & & \\
\hline & None & $15(54)$ & \\
\hline & Paracetamol & $5(18)$ & \\
\hline & NSAIDs & $5(18)$ & \\
\hline & Opoids & $2(7)$ & \\
\hline & Others & $1(4)$ & \\
\hline & $\mathrm{X}$-ray grade (n knees, \%) & Inv leg & Uninv leg \\
\hline & No X-rays taken & $0(0)$ & $10(36)$ \\
\hline & KL-grade II & $9(32)$ & $9(32)$ \\
\hline & KL-grade III & $17(61)$ & $8(29)$ \\
\hline & KL-grade IV & $2(7)$ & $1(4)$ \\
\hline & Act mod int, $\min / \mathrm{wk}, \mathrm{M}(\mathrm{SD})$ & $286.0(169.1)$ & \\
\hline & TSK fear of movement, M (SD) & $24.4(7.6)$ & \\
\hline & Endurance 6MWT, m, M (SD) & $642.5(94.6)$ & \\
\hline & KOOS-Symptoms, M (SD) & $59.0(19.1)$ & \\
\hline & KOOS-Pain, M (SD) & $58.8(18.8)$ & \\
\hline & KOOS-ADL, M (SD) & $68.6(21.7)$ & \\
\hline & KOOS-Sport/Rec, M (SD) & $31.5(20.3)$ & \\
\hline & KOOS-QoL, M (SD) & $43.8(18.6)$ & \\
\hline & Örebro PsychoSocial, M (SD) & $39.0(12.7)$ & \\
\hline & EUQOL Gen-H-QoL, M (SD) & $32.1(4.4)$ & \\
\hline
\end{tabular}

$41 \overline{2}$

413 Notes. Case-group $=$ patients with knee osteoarthritis; control-group $=$ individuals without knee complaints; ICF

$414=$ the International Classification of Function, Disability, and Health of the WHO; M = mean; BMI = body mass 415 index; NSAIDs = Non-Steroid Anti-Inflammatory Drugs; KL = Kellgren-Lawrence osteoartrhritis radiographic

416 Grade, Act mod int = Activity level in moderate intenstity recorded by acceleromater (in minutes per week), 
KOOS $=$ Knee Osteoarthritis Outcome Score, 0 to 100 scale, worst to best; ADL = Activity of daily life (subscale of KOOS); Sport/Rec = Sports and Recreation; QoL = (knee related) Quality of Life; Örebro PsychoSocial $=$ Örebro (psychosocial difficulties) Musculoskeletal Pain Questionnaire 10-item version, 1 to 100 scale, best to worst; $\mathrm{M}$ = mean; $\mathrm{SD}$ = standard deviation; Inv. leg = involved or most affected leg; Uninv. leg = uninvolved leg or least affected leg.

\section{Adjusted relations}

A hierarchical (sequential or "Enter") multivariable linear regression was employed to explore the extent of unique explained variance of the addition of information about psychosocial difficulties, then various joint-strength directions, improved the prediction of activities of daily life beyond that afforded by information about knee-specific pain. Table 2 indicates the relationship of the simple regression model (cf. Table 2, model 1), meaning that for every 1point increase (improvement) in KOOS-pain function, the ADL-score is estimated to increase by 0.94 point $(\mathrm{p}<0.001)$. That simple/unadjusted model explained about $66 \%$ of the variability in activities of daily life (cf. the adjusted $\mathrm{R}^{2}$ ). Further, the indicated relationship of that two-predictor model (Table 2, model 2) mean that, when keeping pain fixed/adjusting for pain, every 1-point increase in psychosocial difficulties the ADL-score is estimated to decrease (worsen) by 0.63 point $(\mathrm{p}<0.05)$. This two-predictor model explained about $71 \%$ of the variance in activity of daily life, an increase of $5 \%$ from model 1 . Thereafter, the indicated relationship of the best-fitting three-predictor model (cf. Eq. 2, and Eq. 3 cf. e-appendix), when keeping pain and psychosocial difficulties fixed, meant that for every $0.1 \mathrm{Nm} / \mathrm{kg}$ increase in hip external rotation strength the ADL-score is estimated to increase by 5.98 points $(\mathrm{p}<0.01)$. This "best" model (M3.1, Table 2$)$ explained on average $78 \%$ of the total variance in activity of daily life. When its effect estimates were reported in a standardized unit (standardized betas, Table 2), the latter showed that pain, respectively, explained 1.4 times more of the SR-ADL-outcome than psychosocial difficulties and 1.5 times more (of the 
443 outcome) than hip external rotation strength. Table 2's model 3.1 to 3.8 exhibit the top-down 444 rank of the unique explained variance of the joint-strength actions on the SR-ADL-outcome, 445 with the hip external rotation $8 \%$; ankle eversion, hip internal rotation, and ankle inversion 446 each 4\%; ankle plantar flexion 3\%; hip abduction and knee flexion each 2\%, and knee 447 extension strength $1 \%$. The two first relationships were statistically significant or 448 generalizable, the next two borderline-significant, whereas the last four were clearly not 449 significant. In the models of the current main analysis, there were high consistency between 450 the four presented effect magnitude indicators (i.e., adjusted $\mathrm{R}^{2}$, unique variance explained, 451 standardized beta, and p-values) [Table 2]. 
Table 2. Exploratory prediction of activity of daily life by strength while controlling for pain and psycosocial difficulties in a multiple linear regression analysis. Strength models are ranked acc. to avg. of four effect estimates (best-worst, top-down).

\begin{tabular}{|c|c|c|c|c|c|c|c|c|c|c|c|c|c|c|c|}
\hline Mod no & $\begin{array}{l}\text { Intercept and } \\
\text { predictors }\end{array}$ & Adj $R^{2}$ & $\mathrm{~F}$ & $\begin{array}{l}\mathrm{P} \text { of } \\
\text { model }\end{array}$ & $\mathrm{F} \Delta$ & $\begin{array}{l}\text { Uniq } \\
\text { var or } \\
\Delta \mathrm{R}^{2}\end{array}$ & $\mathrm{P}$ of $\mathrm{F} \Delta$ & Unstd b & SE & Std B & LL & UL & $\mathrm{t}$ & $\begin{array}{l}\text { P of } \\
\text { coeff }\end{array}$ & $\frac{\mathrm{R}}{\mathrm{Md}}$ \\
\hline \multirow[t]{2}{*}{1} & Constant & 0,659 & 50,22 & $1,6 \mathrm{E}-07$ & 50,22 & 0,659 & $1,6 \mathrm{E}-07$ & 13,27 & 8,17 & 1,62 & $-3,53$ & 30,08 & 1,62 & 0,1165 & \\
\hline & KOOS-pain & & & & & & & 0,94 & 0,13 & 0,81 & 0,67 & 1,21 & 7,09 & $1,6 \mathrm{E}-07$ & \\
\hline \multirow[t]{3}{*}{2} & Constant & 0,711 & 34,14 & $7,1 \mathrm{E}-08$ & 6,82 & 0,073 & 0,015 & 55,13 & 17,65 & & 18,79 & 91,48 & 3,12 & 0,0045 & \\
\hline & KOOS-pain & & & & & & & $0, \hat{5} 5$ & 0,16 & 0,56 & 0,31 & 0,99 & 3,96 & $5,5 \mathrm{E}-04$ & \\
\hline & Psychosoc diffic & & & & & & & $-0,63$ & 0,24 & $-0,37$ & $-1,13$ & $-0,13$ & $-2,61$ & 0,015 & \\
\hline \multirow[t]{5}{*}{3.1} & Constant & 0,784 & 33,62 & $9,3 E-09$ & 9,46 & 0,076 & 0,0052 & 42,27 & 15,82 & & 9,63 & 74,91 & 2,67 & 0,013 & \\
\hline & KOOS-pain & & & & & & & 0,58 & 0,14 & 0,50 & 0,28 & 0,87 & 4,02 & $5,1 \mathrm{E}-04$ & \\
\hline & Psychosoc diffic & & & & & & & $-0,58$ & 0,21 & $-0,34$ & $-1,01$ & $-0,14$ & $-2,74$ & 0,011 & \\
\hline & Hip ext rot str & & & & & & & 59,84 & 19,46 & 0,29 & 19,68 & 100,00 & 3,08 & 0,0052 & \\
\hline & Rank & 1 & & & & 1 & & & & 1 & & & & 1 & 1 \\
\hline \multirow[t]{5}{*}{3.2} & Constant & 0,744 & 27,15 & $6,9 \mathrm{E}-08$ & 4,26 & 0,040 & 0,050 & 45,95 & 17,18 & & 10,48 & 81,42 & 2,67 & 0,013 & \\
\hline & KOOS-pain & & & & & & & 0,57 & 0,16 & 0,49 & 0,24 & 0,90 & 3,59 & 0,0015 & \\
\hline & Psychosoc diffic & & & & & & & $-0,56$ & 0,23 & $-0,33$ & $-1,04$ & $-0,09$ & $-2,44$ & 0,022 & \\
\hline & Ankle ever str & & & & & & & 57,64 & 27,94 & 0,22 & $-0,03$ & 115,31 & 2,06 & 0,050 & \\
\hline & Rank & 2 & & & & 2 & & & & 3 & & & & 2 & 2 \\
\hline \multirow[t]{5}{*}{3.3} & Constant & 0,741 & 26,72 & $8,0 \mathrm{E}-08$ & 3,92 & 0,038 & 0,059 & 47,04 & 17,19 & & 11,56 & 82,53 & 2,74 & 0,012 & \\
\hline & KOOS-pain & & & & & & & 0,52 & 0,17 & 0,45 & 0,17 & 0,86 & 3,05 & 0,0055 & \\
\hline & Psychosoc diffic & & & & & & & $-0,58$ & 0,23 & $-0,34$ & $-1,06$ & $-0,11$ & $-2,53$ & 0,018 & \\
\hline & Hip int rot str & & & & & & & 18,98 & 9,59 & 0,24 & $-1,06$ & $-0,11$ & 1,98 & 0,059 & \\
\hline & Rank & 3 & & & & 3 & & & & 2 & & & & 3 & 3 \\
\hline 3.4 & Constant & 0,739 & 26,48 & $8,7 \mathrm{E}-08$ & 3,72 & 0,036 & 0,066 & 53,01 & 16,79 & & 18,35 & 87,67 & 3,16 & 0,0043 & \\
\hline & KOOS-pain & & & & & & & 0,53 & 0,17 & 0,46 & 0,19 & 0,88 & 3,18 & 0,0040 & \\
\hline & Psychosoc diffic & & & & & & & $-0,68$ & 0,23 & $-0,40$ & $-1,16$ & $-0,20$ & $-2,94$ & 0,0072 & \\
\hline & Ankle inv str & & & & & & & 44,77 & 23,21 & 0,21 & $-3,15$ & 92,68 & 1,93 & 0,066 & \\
\hline & Rank & 4 & & & & 4 & & & & 4 & & & & 4 & 4 \\
\hline 3.5 & Constant & 0,731 & & & 2,95 & 0,029 & 0,099 & 51,29 & 17,14 & & 15,91 & 86,67 & 2,99 & 0,0063 & \\
\hline & KOOS-pain & & & & & & & 0,52 & 0,18 & 0,45 & 0,16 & 0,88 & 2,96 & 0,0069 & \\
\hline & Psychosoc diffic & & & & & & & $-0,61$ & 0,23 & $-0,36$ & $-1,09$ & $-0,13$ & $-2,60$ & 0,016 & \\
\hline & Ankle $\mathrm{pl}$ flX str & & & & & & & 18,94 & 11,03 & 0,21 & $-3,83$ & 41,71 & 1,72 & 0,099 & \\
\hline & Rank & 5 & & & & 5 & & & & 4 & & & & 5 & 5 \\
\hline 3.6 & Constant & 0,722 & 24,40 & $1,8 \mathrm{E}-07$ & 2,04 & 0,021 & 0,166 & 52,18 & 17,41 & & 16,24 & 88,11 & 3,00 & 0,0063 & \\
\hline & KOOS-pain & & & & & & & 0,57 & 0,17 & 0,49 & 0,21 & 0,92 & 3,31 & 0,0029 & \\
\hline & Psychosoc diffic & & & & & & & $-0,66$ & 0,24 & $-0,38$ & $-1,15$ & $-0,17$ & $-2,76$ & 0,011 & \\
\hline & Hip abd str & & & & & & & 9,79 & 6,84 & 0,16 & $-4,34$ & 23,91 & 1,43 & 0,166 & \\
\hline & Rank & 6 & & & & 6 & & & & 6 & & & & 6 & 6 \\
\hline 3.7 & Constant & 0,718 & 23,96 & 2,1E-07 & 1,69 & 0,018 & 0,206 & 48,83 & 18,07 & & 11,54 & 86,12 & 2,70 & 0,012 & \\
\hline & KOOS-pain & & & & & & & $0, \hat{3} 1$ & 0,16 & 0,53 & 0,27 & 0,95 & 3,72 & 0,0011 & \\
\hline & Psychosoc diffic & & & & & & & $-0,62$ & 0,24 & $-0,36$ & $-1,12$ & $-0,13$ & $-2,60$ & 0,016 & \\
\hline & Knee flex str & & & & & & & 6,84 & 5,26 & 0,14 & $-4,01$ & 17,69 & 1,30 & 0,206 & \\
\hline & Rank & 7 & & & & 7 & & & & 7 & & & & 7 & 7 \\
\hline 3.8 & Constant & 0,712 & 23,25 & $2,8 \mathrm{E}-07$ & 1,12 & 0,012 & 0,300 & 52,16 & 17,83 & & 15,37 & 88,95 & 2,93 & 0,0074 & \\
\hline & KOOS-pain & & & & & & & 0,31 & 0,17 & 0,52 & 0,26 & 0,95 & 3,61 & 0,0014 & \\
\hline & Psychosoc diffic & & & & & & & $-0,65$ & 0,24 & $-0,38$ & $-1,15$ & $-0,15$ & $-2,66$ & 0,014 & \\
\hline & Knee ext str & & & & & & & 4,32 & 4,54 & 0,11 & $-4,56$ & 14,20 & 1,06 & 0,300 & \\
\hline & Rank & 8 & & & & 8 & & & & 8 & & & & 8 & 8 \\
\hline
\end{tabular}

Notes: The outcome is self-reported function in activity of daily life from the Knee Injury and Osteoarthritis Outcome Score (KOOS). The colored cells highlights the four effect estimates. Mod no = the linear regression model numbers; Adj R2 = Adjusted total explained variance, where 1 is maximum and 0 minimum; F = F-ratio, a test statistics with a known probability distribution; $P=$ probability (or significance) value for observing the result given the rullhypothesis is true; $F \Delta=$ Change in F-ratio by the last variable added to the model; $\Delta \mathrm{R} 2$ change in $\mathrm{R}$-squared or change in coefficient of multiple determination or the unique variance explained by the model by the last added factor (cf. strength); Unstd $b=$ unstandardized beta, the slope of the line, an effect measure of relationship; SE = Standard error; Std B = the standardized coefficient Beta, an effect estimate of relationship, standardized by its SE; Cl = confidence interval; $\mathrm{LL}=$ lower limit; $\mathrm{UL}=$ upper limit, $\mathrm{t}=\mathrm{t}$-value or test statistics with a known probability distribution; coeff = coefficient; Ro rank of the original model; Rs rank of the sensitivity model; Psychosoc diffc = psychosocial difficulties, a predictor variable or a covariate or control variable in the linear regression model or equation; str = strength. 
455

456 With age in the two-candidate predictor model S2 (cf. Table 3, model 2), keeping KOOS-pain

457 fixed, the relationship estimated that a year increase in age reduced SR-ADL function by 0.48

458 point, but the relationship was not significant. Specifically, age added only $1.9 \%$ uniquely

459 explained variance to the KOOS-pain-only model (in contrast to the $7.6 \%$ for psychosocial

460 difficulties). In the three-predictor sensitivity-model, age was even weaker related to SR-

461 ADL. Therein, the two strength actions with the highest unique explained variance were still

462 hip external rotation and ankle eversion strength which explained about the same unique

463 variance as before, but only the first was clearly significant (Table 3). There was, however, a

464 marked change in rank for knee flexion strength, going from the seventh (in the original

465 model) to the third rank, although its relationship was still not significant. Other changes in

466 rank were negligible.

467

468

Table-3-in-here 
Table 3. Exploratory prediction of activity of daily life by strength while controlling for pain and age via multiple linear regression sensitivity analysis. Strength variables are ranked according to the average of four effect estimates (best-worst, top-down).

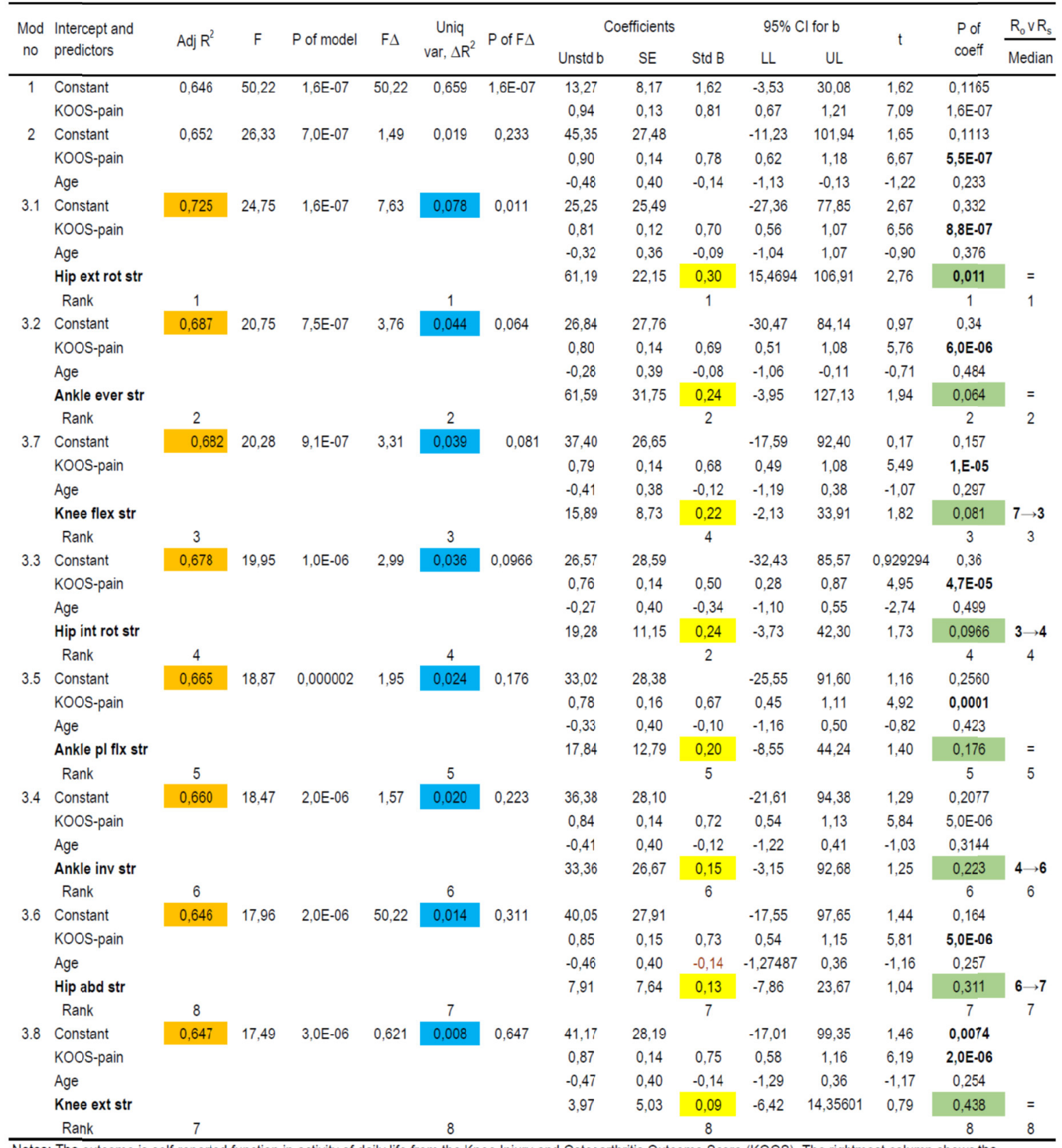

Notes: The outcome is self-reported function in activity of daily life from the Knee Injury and Osteoarthritis Outcome Score (KOOS). The rightmost column shows the differences in rank between original and sensitivy models. The colored cells highlights the four efect estimates. Mod no $=$ the linear regression model numbers; $A d j R^{2}=$ Adjusted total explained variance, where 1 is maximum and 0 minimum; $F=F$-ratio, a test statistics with a known probability distribution; $P=$ probability (or significance) value for observing the result given the null-hypothesis is true; $F \Delta=$ Change in F-ratio by the last variable added to the model; $\Delta R^{2}$ change in $R$-squared or change in coefficient of multiple determination or the unique variance explained by the model by the last added factor (cf. strength); Unstd $b=$ unstandardized beta, the slope of the line, an effect measure of relationship; SE = Standard error; Std B = the standardized coefficient Beta, an effect estimate of relationship, standardized by its SE; $\mathrm{Cl}=$ confidence interval; $\mathrm{LL}=$ lower limit; $\mathrm{UL}=$ upper limit, $\mathrm{t}=\mathrm{t}$-value or test statistics with a known probability distribution; coeff = coefficient; $\mathrm{R}_{0}$ rank of the original model; $\mathrm{R}_{\mathrm{s}}$ rank of the sensitivity model; Psychosoc diffc = psychosocial difficulties, a predictor variable or a covariate or control variable in the linear regression model or equation; str = 
471

472

473

474

475

476

477

478

479

480

481

482

483

484

485

486

487

488

489

490

491

492

493

494

\section{Discussion}

\section{Principle findings}

The principle findings, mutually adjusted for KOOS-pain and psychosocial difficulties, showed that the most substantial muscle strength potential predictions on the outcome SRADL were inferred for hip external rotation and ankle eversion strength, somewhat less substantial and borderline significant (were such) for hip internal rotation and ankle inversion strength, and least and not significant relations for the ankle plantar flexion, hip abduction, knee flexion and knee extension strength. Of potential biopsychosocial clinical importance, on average the current 3 best prediction models explained the following substantial proportions of variance in the SR-ADL-outcome: 1) KOOS-pain alone, 66\%; 2) KOOS-pain and psychosocial difficulties, 71\%; and 3) KOOS-pain, psychosocial difficulties, and hip external rotation strength, $78 \%$. Apparently, this is the first study to comprehensively report biopsychosocially adjusted cross-sectional predictive potentials of muscle strength on the prime outcome SR-ADL function for patients with KOA. (The e-appendix reports such findings for the bivariate analyses.)

\section{Internal validity}

There are several strengths of this study. The current statistical model and the sample size were adjusted to each other in order to detect substantial relationships as statistically significant. Further, our current overview of background knowledge allowed us to consider several candidate prediction variables (31) that have documented prospective relationships and important therapeutic effects $(24,25,76,77)$ on the SR-ADL-outcome. Yet further, our choice of candidate predictors incorporated knowledge of the most discriminative variables in two prior case-vs-healthy control exploratory studies on the same sample $(28,40)$. Moreover, 
the KOOS-SR-ADL outcome is highly recommended by reputable health profession guidelines (95-97), research organization guidelines $(62,98,99)$, and patient associations (99) [in contrast to the KOOS-Recreation/Sport and -KR-QoL functions]. Even further, the measurement instrument subscales KOOS-ADL and KOOS-pain were both knee and OA specific [in contrast to WOMAC-PF and Pain-VAS] (64). Additionally, the relationship between a comprehensive set of single muscle strength actions and the outcome were adjusted for variables estimated to explain a substantial part of the variability in the outcome.

Furthermore, the current strength measurement tools are traceable to measurement standards, reliable without manual influence $(52,53,56)$, and were applied by a 3 person team (cf. Acknowledgement) led by a trained clinical researcher (KV). Yet additionally, the current confounder analysis was based on proper background knowledge $(88,90)$ and applied algorithmic-based software for closing potential non-causal paths $(86,87)$. Finally, the main results were supported by a sensitivity analysis which indicated relatively robust primary findings.

Still, there are several internal validity limitations of the current study. Firstly, we did not formally examine the intra- and inter-reliability for the strength tests of the current test team on the current sample. On the other hand, most laboratories still trust their strength equipment and approaches although most teams have never formally tested each team's such specific performances. Thereto, of ethical and resource reasons we chose not to burden our participants with yet another set of our extensive strength measures. Secondly, the killing threat to the internal validity of true causality is the current cross-sectional design (100). However, we believe true causality requires a well-performed RCT where increased strength of these key muscles may prove clinical important prediction. Third, notwithstanding the current multivariable "best" model, the current study only examined the total or independent relationship between each explanatory/predictor variable and the outcome. "Only”, because 
there might be indirect relationships hidden by the current conventional regression model, effects that can be detected by mediation analysis allowing for inter-relationships between predictive variables $(101,102)$. For example, there might be such serial-coupled relationships between the various muscle strength variables, but also between pain and strength variables, awaiting revelation. However, in order to explore such mediation effects, the sample size of the current study had had to be larger, or we would have had to increase the risks of bias by (i) the small-study effect $(103,104)$ or (ii) overfitting the prediction model (105). Relatedly so, we may have introduced overadjustment bias $(106,107)$ or committed mutual adjustment fallacies (108) when adjusting for KOOS-pain and psychosocial factors as we evaluated the strength relations. A related concern is that smaller potential prediction studies are generally at higher risk of bias than larger studies due to including fewer adjustment factors or copredictors (103). However; for any observational estimates, the validity of analyses depends on assumptions about confounding and selection bias that cannot be empirically verified (109). Forth, there may be important linear regression interactions between the various muscle joint-strength directions. In sum, according to the sample adjusted purpose and approach, we infer adequate internal validity of the current study.

\section{External validity}

On the one hand, the generalizability or external validity of the current findings is substantial considering that both sexes, all GPs' definitions of KOA, all relevant radiological grades, a broad age-range, a broad pain-range, all educational levels, and an upper BMI-range with obesity grade I, were all allowed in order to qualify participants into the study. On the other hand, generalizability is constrained for patients with severe obesity, KOA due to trauma, age outside 45 to 70 years, comorbidities with contraindications for physical activities $(36,110)$, and physical activity limitations disallowing stair negotiation without walking aids. Yet 
545 further, due to limited sample size, we performed no analyses stratified by gender. Most

546 importantly, perhaps, we downgrade the external validity due to the risk of chance findings

547 because of the overall moderate sample size (111) and the less generalizability inferred

548 through the sensitivity analysis. Altogether, we infer low-to-moderate external validity of the

549 current study.

550

551 Results discussion

$552 \quad$ Adjusted cross-sectional relations

553 The adjusted cross-sectional relations found in current study, indicate that hip external

554 rotation and ankle eversion strength have generalizable independent relations with the

555 outcome SR-ADL function. Similar sized relations are also suggested for hip internal rotation

556 and ankle inversion strength, notwithstanding the borderline significance. But no significant

557 relations are indicated for the knee muscles. So, how does the existing multivariable evidence

558 relate to these findings?

559

560 Two large regression-based cross-sectional prediction studies $(58,112)[\mathrm{N}=248,284]$ could

561 have illuminated that question, but only for the knee muscles. That is, if they had reported the

562 unique explained variance of the predictor knee muscle strength on WOMAC-PF and all the

563 accompanying regression coefficients of their model. Unfortunately, they did not. Instead, van

564 der Esch et al. (112) restricted their report to include the adjusted relationship weight only for

565 their focal candidate predictor, self-reported knee instability, thus, inappropriately left out (of

566 the model/result table) the co-predictors pain and muscle strength. Interestingly though, they

567 (112) wrote the following in their Discussion section:

568 "The contribution of self-reported knee instability to the variance in activity

569 limitations over knee pain and muscle strength was small. The most important 
contributors to the variance in activity limitations are knee pain and muscle strength." [p. $1509(112)]$ Specifically, their (112) predictive model included pain-VAS and muscle strength as the mean of isokinetic concentric knee flexion and extension peak torques at $60 \% \mathrm{~s}(\mathrm{Nm} / \mathrm{kg})$. Compared to the current study, which applied the KOA-specific predictor KOOS-pain (which explained 66\% alone) and the KOOS-ADL-outcome, their full "best" model explained only $47 \%$ of the total variance in WOMAC-PF, where self-reported knee instability explained 4\%, thus left $43 \%$ to be explained by pain-VAS and knee muscle strength which is substantially less than the KOOS-pain alone in the current study. The difference in choice of measures might explain the pain predictors' difference in explained variances. Because of their (112)

580 inappropriate reporting of the proportion of explained variance of knee muscle-strength on SR-ADL, their results are unfortunately not comparable to ours not significant findings on knee strength (112).

In the second large cross-sectional prediction-model study, Sanchez-Ramirez et al.'s (58) model included two predictors, the one-leg stance-test ( $0=$ cannot stand for $30 \mathrm{~s}, 1=$ can so) and knee muscle strength [combined, cf. (112)], onto the WOMAC-PF-outcome. Their independent relationship of the one-leg stand test was not significant $(\mathrm{p}=0.09)$ and the relationship weight (“effect” magnitudes) for muscle strength similarly unreported, as were standardized betas, the various unique $\mathrm{R}^{2}$, and the $\mathrm{p}$-value of the model. Thus, the latter study is similarly incomparable to ours on knee strength.

Clearly, the limitations in reporting in the above-cited cross-sectional prediction model

591 studies should be understood in light of the reporting and evaluation standards for such

592 studies were underdeveloped in medical research until recently $(103,105,113-115)$ compared

593 to common bivariate analyzed RCTs and systematic reviews. Importantly, both studies above

$594(58,112)$ applied the data-driven decision rule that if a potential confounder change the 
regression coefficient of the modeled candidate predictors (i.e. self-reported knee instability, knee pain, or muscle strength) by more than $10 \%$, then this variable is classified as a confounder (116). Thus, because the WOMAC-PF predicting model of knee instability, pain, and knee muscle strength in the van der Esch et al. study (112) did not report confounders, we can infer that neither joint proprioception, joint varus-valgus laxity, age, sex, BMI, duration of complaints, nor radiographic severity had an important impact on these relations. Although van der Esch et al. (112) reported to have performed a causal diagram analysis, they still chose to keep those factors out of the model (or result table) due to a data-driven rule. Apparently, further methodological research and PROBAST papers $(113,115)$ need a clearer definition of confounding as well as criteria for selection, adjustment, and reporting of such factors. Hopefully, the importance of our confounding discussion will be clearer to the nonresearch reader after the result discussion below.

\section{Adjusted prospective knee extension strength relations}

Adjusted prospectively, in a recent systematically reviewed and meta-analysis, Culvenor et al. (21) documented a trivial (18) and heterogeneous increased risk of WOMAC-PF worsening (incline) with lower knee extension strength in patients with, or at high risk of, KOA (OR 1.4 $95 \%$ CI $\left.1.0-1.9 ; \mathrm{I}^{2}=88.4 \% ; \mathrm{p}<0.001\right)$. The methodological evaluation of the 4 included studies (117-120) [N>6 500, 42\% women, mean age 62-69 years, specialist care centers] showed $3(117,118,120)$ of 4 studies to be of high-quality. However, altogether these adjusted for 30 confounders where table 4 shows that only 8 of these (28\%) were reported by more than one study. Thus, due to high statistically heterogeneity, Culvenor et al. (21) concluded that 3 high-quality studies showed conflicting evidence for the trivial relationship between lower knee extension strength and SR-ADL function. Further, the diversity and volume of confounders in their reviewed studies seem troublesome indeed. In sum, the 
620 conflicting prospective evidence of trivial knee extensor strength and SR-ADL supports the 621 not significant findings for knee strength found in the current study.

622

623

624

625

626

627

628

629

630

631

632

633

634

635

636

637

638

639

640

641

642

643

644 
Table 4. Factors adjusted for in prognostic studies of ADL-function for patients with KOA in the systematic review of Culvenor et al. (2017).

\begin{tabular}{|c|c|c|c|c|c|c|}
\hline $\begin{array}{l}\text { No } \\
\text { CV }\end{array}$ & Confonding variables (CV) & $\begin{array}{l}\text { Colbert } \\
(2012)\end{array}$ & $\begin{array}{l}\text { Sharma } \\
(2003)\end{array}$ & $\begin{array}{l}\text { White } \\
(2010)\end{array}$ & $\begin{array}{c}\text { Thomas } \\
\text { (2008) }\end{array}$ & $\begin{array}{l}\text { No of } \\
\text { studies }\end{array}$ \\
\hline 1 & Age (years) & $\checkmark$ & $\checkmark$ & $\checkmark$ & & 3 \\
\hline 2 & Body mass index $\left(\mathrm{kg} / \mathrm{m}^{2}\right)$ & $\checkmark$ & $\checkmark$ & $\checkmark$ & & 3 \\
\hline 3 & Comorbidity score & $\checkmark$ & $\checkmark$ & & & 2 \\
\hline 4 & Depression (yes/no) & $\checkmark$ & & $\checkmark$ & & 2 \\
\hline 5 & Pain, foot (yes/no) & $\checkmark$ & & $\checkmark$ & & 2 \\
\hline 6 & Pain, hip (yes/no) & $\checkmark$ & & $\checkmark$ & & 2 \\
\hline 7 & Race (caucasian, other) & $\checkmark$ & & $\checkmark$ & & 2 \\
\hline 8 & Sex (male/female) & $\checkmark$ & & $\checkmark$ & & 2 \\
\hline 9 & Activity, physical & $\checkmark$ & & & & 1 \\
\hline 10 & Aerobic exercise & & $\checkmark$ & & & 1 \\
\hline 11 & Alcohol intake & $\checkmark$ & & & & 1 \\
\hline 12 & Comorbidity (none, $\geq 1$ ) & & & $\checkmark$ & & 1 \\
\hline 13 & Disease severity & & $\checkmark$ & & & 1 \\
\hline 14 & Falls (no.) & $\checkmark$ & & & & 1 \\
\hline 15 & Joint space grade 1 [vs 0] & $\checkmark$ & & & & 1 \\
\hline 16 & Joint space grade 2 [vs 0] & $\checkmark$ & & & & 1 \\
\hline 17 & Knee confidence* & $\checkmark$ & & & & 1 \\
\hline 18 & Knee injury (yes/no) & $\checkmark$ & & & & 1 \\
\hline 19 & Knee laxity & & $\checkmark$ & & & 1 \\
\hline 20 & Knee surgery (yes/no) & $\checkmark$ & & & & 1 \\
\hline 21 & Mental health & & $\checkmark$ & & & 1 \\
\hline 22 & Pain intensity, knee (scale) & & $\checkmark$ & & & 1 \\
\hline 23 & Pain, ankle (yes/no) & $\checkmark$ & & & & 1 \\
\hline 24 & $\begin{array}{l}\text { Pain, bilateral knee } \\
\text { (yes/no) }\end{array}$ & & & & $\checkmark$ & 1 \\
\hline 25 & Pain, low back (yes/no) & & & $\checkmark$ & & 1 \\
\hline 26 & Pain, WOMAC score & $\checkmark$ & & & & 1 \\
\hline 27 & $\begin{array}{l}\text { Proprioceptive acuity }\left(^{\circ}\right. \\
\text { error) }\end{array}$ & & $\checkmark$ & & & 1 \\
\hline 28 & Self-efficacy (scale) & & $\checkmark$ & & & 1 \\
\hline 29 & Stiffness after resting & & & & $\checkmark$ & 1 \\
\hline 30 & $\begin{array}{l}\text { Stiffness, duration of } \\
\text { morning }\end{array}$ & & & & $\checkmark$ & 1 \\
\hline Sum & of confounders per study & 17 & 11 & 9 & 3 & \\
\hline
\end{tabular}

Notes. Sorted for 1 th) no. of studies 2 nd) Confounders alphabetically. $*=$ a subquestion of the KOOS-quality of life subscale, \# = Center for Epidemiological Studies Depression, CES-D, score $\geq 16$, yes/no. 


\section{Adjusted prospective hip strength relations}

The prospective adjusted relations between the predictor hip muscle strength and the selfreported ADL-outcome in patients with KOA, is sparse. In a systematic review of prognostic factors for progression of clinical KOA, Bastick et al. (36) reported two studies $(121,122)$ with only knee extension strength data. None showed a significant association with WOMACPF [one high-quality (121), one low-quality (122); $\mathrm{N}=502]$. Thus, no such studies including hip muscle strength data was found (36). More recently, a prospective cohort study by Chang et al. (91) documented significant relation of trivial magnitude (18) between baseline hip abductor strength with baseline-to-5-year poor outcomes on SR-ADL (RR 0.94, 95\%CI 0.88 to $0.99, \mathrm{~N}=187$ ). The authors' wrote that theirs' was the first long-term study reporting a protective effect of hip abductor strength on poor SR-ADL function in patients with knee OA. The trivial effect magnitude, however, is concurrent with the low unique variance explained $(2 \%)$ of such ADL function by hip abductor strength in the current study, indicating low importance of hip abduction strength on SR-ADL.

\section{Therapeutic RCT-findings vs mechanisms vs the current results}

What is the link between the current study's strength potentials vs the findings in a recent systematic review of RCTs regarding the effect of strengthening therapy on SR-ADL for patients with KOA? Hislop et al. (123) meta-analyzed 5 trials indicating that adding hip to knee extension strengthening as compared to knee extension strengthening alone moderately (18) improve SR-ADL function, although the effect was borderline significant (SMD -0.74, $95 \% \mathrm{CI}-1.56$ to 0.08$)$. The quality was high in two studies $(124,125)$ [PEDro score $>6$ ] and low in three $(27,126,127)$. Highly potentially important, a sub-analysis of these data showed that the single study with the highest effect-size [high (18)] on both pain and SR-ADL, was found for the high intensity-resistance (10RM) strength exercise program of Ashok (27). The 
670 latter program potentially strengthens all the muscles found potential predictive in the current

671 study. But why that is probable, must be thoroughly explained in order to be believed:

abductor strengthening in side-lying (ankle weight-cuff) and standing (a rubber-band around

674 the ankles) as well as knee extension strengthening in sitting (ankle cuffs) [dose: 10RM

675 resistance $\times 10$ reps $\times 3$ series/muscle group], followed by a standing isometric $90^{\circ}$ flexed-hip so-called hip-abduction exercise against the wall (dose: maximum effort $\times 10 \sec \times 10$ reps $\times 3$ series/an host of muscle groups). According to clinical-biomechanical analyses $(128,129)$, the corresponding author's self-training experience, and EMG from non-human primates (130),

679 the flexed-hip wall-abduction-exercise probably highly activates the abductors of the flexed 680 hip [the gluteus maximus $(128,131)$ and the quadriceps coxa $(129)]$ in a force-length 681 advantaged position $(17,129,132)$ on the non-stance-leg, thus inducing a forceful rotational 682 stimuli onto the stance-leg, which then co-activates its hip external and internal rotators 683 (including gluteus maximus), hip abductors, knee abductors, and ankle invertor-evertor 684 muscles in a gait-important near-anatomical-zero-position. Performed bilaterally, Ashok's 685 (27) simple and feasible program thus potentially improve muscle strength in the mechanism686 triggering directions needed for stabilizing and strengthen the lower-limb kinetic chain in the 687 transverse, frontal, and sagittal plane. Thus, counteracting knee instability (133), imbalanced 688 muscle activation (134), weakness in hip-rotator muscles $(28,135)$, knee extensors (20), ankle 689 invertor-evertors (28), knee abductors (136), and the so-often left out, regularly moderate690 intensity cyclic mechanical stress and rest [i.e., training (137)] of the knee connective-tissue 691 converting DNA-replicating adaptive proliferation and remodeling signals [i.e., 692 mechanotransduction (138-140) repair/strengthening]. Or, put shortly, targeted the plausible 693 biomechanical mechanisms for KOA. 
695 Similarly mechanism-important and -supportive of the current study's potential predictive

696 strength-findings, is the strengthening trial of Snyder et al. (141). Our claim again demands a

697 proper explanation. It is well known that several hip abduction strengthening programs have

698 failed to reduce the external knee adduction moment (EKADM) during gait in patients with

699 KOA, although it is proven to be related to increased medial tibiofemoral disease progression

700 [although not causally] (142). Promising is a high quality one-group before-and-after strength

701 and kinetic-kinematic analysis study (141) [Snyder et al.] which findings concur with those of

702 the current study regarding the potential importance of proper hip rotator and ankle inversion-

703 eversion muscle strength. Because, in healthy moderately active females, it (141) documented

704 a significant moderate (18) decrease in rearfoot inversion moment (Cohen's $d$ 0.8, $81 \%$

705 within-group difference [WGD]) and a significant small (18) decrease in the EKADM

706 (Cohen's $d 0.5,10 \%$ WGD, p=0.05) during running after 6 weeks with three large range-of-

707 motion (17) hip strengthening exercises. Importantly, what might have been the potential key

708 differences between the strengthening exercises offered by Snyder et al. (141), reducing the

709 EKADM during running, and for example Bennell et al. (143), who, in a high methodological

710 quality RCT, showed no change in EKADM during gait?

711 We suggest that the Snyder et al.'s (141) program properly strength-exercised all the

712 muscle-actions found potentially predictive in the current study. The exercises targeted the hip

713 rotators eccentric-and-concentrically in single-leg stance. Thus, it must also have strengthened

714 the ankle invertor-evertor muscles during single-leg-stance rotations. (Of cause also the hip

715 abductors, but that is not the main point here.) In contrast, Bennell et al.'s $(143,144)$ program

716 apparently only loaded the hip abductors and adductor muscles in the frontal plane. Moreover,

717 Snyder et al. (141) confined their strength dose onto each muscle group via one targeting

718 exercise, only once per session (although via 3 sets). Specifically, the program induced an

719 objective strength-dose per muscle-group of $60 \%$ of $1 \mathrm{RM}$ resistance $\times 10$ to 30 repetitions $\times 3$ 
sets, one-to-one supervised by an in-clinic instructor. The instructor retested $1 \mathrm{RM}$ every $2^{\text {nd }}$ week. Each session was performed 3 times per week, thus the program allowed adequate restitution time between sessions $(>48 \mathrm{~h})$. In 6 weeks, this led to moderate strength increase in hip abduction (Cohen's $d 0.7,15 \% \mathrm{WG}, \mathrm{p}=0.009)$ but a more substantial increase in external rotation strength (Cohen's $d 1.0,23 \% \mathrm{WG}, \mathrm{p}<0.0005)$. Unfortunately, Snyder et al. (141) did not test for increased hip internal rotation strength, probably because they were unaware that their "AWAY exercise" exercised that muscle-group (not the hip external rotation muscles). In contrast, Bennell et al. (143) strength-dosed [resistance $\times$ repetitions $\times$ sets/muscle group (13, 16, 145)] the hip abductors more than 6 times higher that of Snyder et al. (141), while obtaining only $13 \%$ within-group strength improvement after twice as long intervention period (12 vs 6 weeks). [For ref. (143) we assumed 10RM is $\sim 80 \%$ of $1 \mathrm{RM}(146,147)$ and 4 hip-abductor-exercises 5 times-a-week.) Bennell et al.’s (143) between-group difference on hip abductor strength was small (18) [SMD 0.33, 95\%CI -0.08 to 0.75]. Although they (143) also applied the same isometric single-stance flexed-hip wall abduction exercise as Ashok (27), their (143) much larger than optimal weekly abductor muscle training dose $(145,148$ 151) likely also unintentionally induced an inappropriately high strength dosage on the hip rotators and ankle inversion-eversion muscles due to synergistic actions [i.e., tipped towards overtraining $(23,145)]$. In support of such a view, the sub-data of a systematic review of interventions for knee-pain (152) demonstrate that a simple 2-exercise only program [by Khayambashi et al. (153): bilaterally; 1 hip abduction exercise, 1 hip external rotation exercise, 30 min exercise session] with 3 sessions per week for 8 weeks (session dose: 20 to $25 \mathrm{RM}$ resistance $\times 20$ to 25 repetitions $\times 3$ sets/muscle group), resulted in a large(18) effect on hip abduction strength compared to an inactive control group (SMD 1.5, 95\%CI 0.7 to 2.4). Within Khayambashi et al.'s (153) intervention group, we found a 28\% increase on the right/dominant side vs a 35\% increase on the left/non-dominant side. Further supportive, a 
meta-regression of RCTs (23) proved that $35 \%$ to $40 \%$ knee extensor improvement in KOApainful knees is achievable within 12 weeks with focused (per muscle-group confined) strength exercise dosage of $60 \%-75 \%$ of $1 \mathrm{RM}$ resistance $\times 10$ to 12 repetitions $\times 3$ sets $\times 3$ sessions per week. Potentially highly important, in sum there seems to be a realistic potential of reducing the EKADM in patients with medial KOA if one properly strength-dose (23) the hip and knee abductors, internal rotators, and external rotators, with one exercise per musclegroup (145) in standing positions that also adequately strength-dose the synergists of the lower limb. That is, with an eccentric-concentric exercise of ambulation-relevant musclelengthening and -shortening. This paragraph-conclusion supports the potential importance of the current study's muscle findings. However, it may also indirectly support the importance of strengthening the knee abductor muscles through a single-leg standing hip abduction exercise.

Further dose-mechanistically, relevant to future studies aiming to confirmatively challenge the findings of the current study, Bartholdy et al. (23) missed the important message of the ACSM referring publications $(148,149,154,155)$ and the dose-response systematic reviews' $(13,145,150,156)$ that a session's dose of strength (training/loading) is defined as resistance $\times$ reps $\times$ sets $/$ muscle group. Pinning strength-dose to a specific muscle group is utterly important. Important is also the impact of range-of-motion on muscle-strengthening and performance (17). Unfortunately, evidence of the length-tension vs. muscle-performance relationship is barely mentioned in the ACSM publications and not properly explained in papers of reporting checklists as Template for Intervention Description and Replication [TIDieR] (157), Consensus on Exercise Reporting Template [CERT] (158), or that of Bartholdy et al. (159). Highly relevant to the current study, given models of prognosis/prediction/treatment of SR-ADL function by any strength factors are to be properly evaluated, multivariable prediction models must at least incorporate the factors of highest 
importance for improving muscle strength. Indeed, the most important factors for properly predicting future strength of a muscle-group is strength dose per session and the number of such strength doses per week - both pinned down to a specific muscle-group $(145,148,160)$. In a recent systematic review and meta-regression analysis(159) of 100 primary studies of 6 926 patients with KOA from 10 clinical guidelines, Bartholdy et al.(159) indicated that poorer exercise-program reporting was associated with greater effects on pain and no association with effects on disability/SR-ADL. However, to help reveal any strength intervention mechanism, the above checklists are in need of evidence from systematic review and metaanalysis of its factors' effects on strength performance. Only with the most important strength predicting factors on the list, researchers should take the effort of repeating the otherwise impressive meta-regressions of exercise interventions by Bartholdy et al. $(23,159)$ onto proper strength exercise interventions. The relevance of such a checklist to the current strength findings seems obvious because only properly dosed strength exercise therapy on the current muscles should be included in future multivariable prediction model studies and treatment trials on the SR-ADL-outcome.

For predictive model studies of SR-ADL function in patients with KOA, researchers should consider the evidence of the underlying mechanism via studies of biomechanics (133-135, $161,162)$, discrimination $(28,163)$, cross-sectional prediction (164), prognosis $(21)$, and systematic review and meta-analysis of randomized trials $(26,85,152)$, which we believe underpins the potential importance of including strength of these hip rotators and ankle inversion-eversion muscle-groups in future multivariable SR-ADL-models for people with symptomatic KOA. 


\section{Possible mechanisms for hip and ankle muscle strength vs SR-ADL relationship}

What might be the detailed potential biomechanical mechanisms behind the relations between hip rotator and the ankle invertor-evertor strength and SR-ADL function that were seen in the current study? We may speculate that the relation signify an "effect" of such muscle strength via the lower limb and knee's instability (133) and muscle recruitment imbalance (134) mechanisms in the frontal plane on the patients SR-ADL function. That is, because these latter concepts are validly documented as potential mechanisms, probably leading to overload of the knee joint due to repetitive stress while walking downhill (133) and flat (134). How these ankle muscles add to frontal plane motor control is easily fathomable (although the muscles are small). But how the hip rotator muscle strength can affect the frontal plane motor control is much harder to grasp. We know from cadaver studies that most of the hip external rotators change their line of action and moment arms with deeper hip flexed positions (129, 165 ) and that four of the external rotators most likely acts like an abductor above $90^{\circ}$ of hip flexion [the quadriceps coxa] (129). However, this does not explain much hip rotator frontalcontrol actions during downhill and flat walking because of the confined hip flexion range-ofmotion during such weight-bearing phases. And if achieving excessive frontal plane strength was the obvious remedy, RCTs with hip abduction strengthening only as the addition to knee exercises would probably show the highest effect sizes on SR-ADL function (and pain) [as compared to quadriceps strengthening exercises only] whereas, as earlier explained, they do not (cf. the rotator-strengthening Ashok trial). Thus, shifting our focus to the transverse plane, we know that ankle invertor-evertor muscles act to control the rotation of the shank, as do the hip rotators to the femur (166). Collectively, we suspect that these muscles mainly control the rotation of the lower limb during walking. In support of such's relevance, muscle simulation studies tell us that the human gait pattern is the least robust to muscle weakness of the hip external rotators [as compared to other muscle-groups] (135). Further, during the 
819 loaded phases of walking, the knee-spanning muscles probably control little rotation of the

820 lower limb and even little such of the knee itself. That is due to the much vertical line of

821 action of these muscles during the normal gait's loaded knee range-of-motion. We thus

822 speculate that proper transverse plane leg strength (hip rotators and ankle invertor-evertors) is

823 necessary (35) for the proper ease of frontal plane knee stability mainly offered by the knee-

824 spanning muscles (167). (Cf. the ease of SR-ADL function.) It is well known that an excess

825 magnitude of (synergist-antagonist-balanced) strength is needed across joints in order to

826 properly (i.e. with ease) stabilize a joint within a limb with multi-jointed degrees of freedom

827 (168). Further, we know that the muscle-groups cooperate with only partly overlapping

828 action-lines to control the various degrees of freedom in all planes simultaneously in

829 functional tasks (168). What we do not know, is how much individuals are allowed to weaken

830 these ankle and hip muscles before they underperform their knee-supportive role, and thus

831 probably induce compensations (168) as increased knee muscle co-contraction (136) and thus

832 micro instability, cartilage degeneration, low-grade inflammation, pain, and decreased SR-

833 ADL function [as the output of the belief, context, and personal factor dependent neuro-

834 endocrine-immune-motor body system] (169). Hopefully, single weight-bearing rotational

835 strength exercising of the lower limb in a gait-relevant hip range of motion $(141,170)$ can

836 prove to be a valuable mechanistic adjunct for improving SR-ADL function in patients with

837 KOA, perhaps through reducing the rotational load on the knee-spanning muscles. Beware

838 though, that knee abduction strength, induced by standing hip abduction resistance, may be a

839 potential co-mechanism.

840

841 On the other hand, one might hypothesize that poor SR-ADL function leads to reduced

842 muscle strength through pain and inactivity (164). That is, that the causal direction is the other

843 way around; that the patients' SR-ADL function is the chicken (the independent variable) and 
844 strength is the egg (the dependent variable). Regarding pain, however, note that the current 845 study did control for the relationship of KOOS-pain vs SR-ADL function before it reported

846 the independent relationship between strength and SR-ADL function. Similarly non-

847 supportive, regarding inactivity, the current patient-sample registered a mean level of

848 accelerometer-recorded moderate intensity physical ADL way above the American

849 recommended weekly average guidance (171) [cf. our study (40)]. The factor vigorous

850 intensity physical ADL-level, on the other hand, was seldom performed by the current

851 patients, thus it was not explored as a factor in the current study. Opposing the importance of

852 the latter, we know from sports that even vigorous regular physical activities are not sufficient

853 (35) for maintaining proper muscle strength in supportive muscles $(33,34)$. The most likely

854 causal factor for maintaining strong muscles is appropriate doses of strength stimuli vs rest

855 per muscle group per week. Thus, currently most injury-prevention programs of the lower

856 limb for athletes acknowledge the need for regular vaccinating targeted muscle strengthening

857 exercises in order to keep strong, injury-free, and healthy $(33,34,172)$. Thus, there seem to

858 be more support of muscle-strength predicting SR-ADL function than the reverse pattern.

859 Nevertheless, as for patellofemoral pain (172), the pathophysiology of KOA is complex with

860 multiple interactive pathways suggested to contribute to its onset and persistence (173). No

861 doubt long-term strong pain and inactivity, especially given no compensating strength-

862 loading, will lead to limited muscle-strength and SR-ADL function.

863

Potential clinical research implications

865 The evidence supporting the current potential prediction model is cross-sectional and

866 explorative and thus confirmative prospective studies of observation and treatment are needed

867 for its validation. However, for now, let's assume the model is valid. What then? How may it

868 possibly be applied? 
870 For prevention and treatment, most obviously, clinician researchers could test people at risk

871 of, or with, KOA (referred from the GPs) on strength on the potential important joint-

872 directions, and, if relevant, put them on a strength exercise programs [e.g. ref. $(141,170)$ ].

873 Preferably, including regular controls or boosting sessions. However, regarding "if relevant",

874 clinical researchers need first to develop reliable, valid, and inexpensive diagnostic isometric 875 strength measurement approaches for the ankle inversion-eversion muscles. For the hip and

876 knee muscles, however, the currently existing isometric dynamometer approaches seems to

877 function adequately [intra-rater reliability, $\mathrm{ICC}_{2,2} 0.84$ to 0.97 and coefficient of variation

$878(\mathrm{CV})<9.8 \%(174) ; \mathrm{ICC}_{2,2} \quad 0.86-0.95$ (175); and inter-tester reliability $\mathrm{ICC}_{2,1} 0.76$ to 0.95 and

879 SEM 5\% to $11 \%$ (56)]. Linked to the dynamometers, however, clinicians urgently need

880 electronically data systems offering instant individual standardized differences on strength/kg

881 vs normative values of age and activity-level matched healthy groups. How else may

882 clinicians say if the strength outputs are relevant?

883

884 For psychosocial variables (and questionnaire data in general) such normative systems

885 fortunately already exist $(47,176)$. Where to evidence-based help towards self-management

886 can be offered according to a recent systematic review (177). For example, for patients with

887 KOA, clinician-based coping skill training has proven moderately effective on the outcome of

888 self-efficacy (178). Whereas internet-based cognitive behavior therapy has proven moderately

889 effective on depression and on psychological distress [in a trial (179) given high methodology

890 and reporting quality (177)]. Both RCTs applied treatment-as-usual as control.

891

892 For pain, through Cognitive functional therapy (CFT) $(173,180)$ clinician researchers may

893 target the pain experience (cf. KOOS-pain and Örebro). Firstly, by helping clients make sense 
894 of pain as something caused by multidimensional biopsychosocial factors that should be remedied by thereto adapted self-management. Therein, pain can be addressed cognitively by

896 clinicians offering hope by a positive evidence-based alternative belief (181) to the currently

897 held misbelief about KOA being an incurable disease of a progressive nature linked to

898 specific causal factors (182). Specifically, based on a huge longitudinal cohort $(\mathrm{N}>1800$

899 participant), White et al. (2010) offer evidence that clinically important improvement is

900 frequent in people with, or at high risk of, KOA (181). Further, pain-reliving hope can be

901 conveyed by the fact that simple and inexpensive endurance exercises have documented the

902 highest standardized effect size on pain (high) compared to wait and see controls seen relative

903 to other exercise modes (183). Moreover, as mentioned above, strengthening exercises of hip

904 and knee muscles has documented large effects on walking performance compared to already

905 known effective quadriceps strengthening control therapy (26). In the same systematic review

906 (26) the latter comparison also proved moderately effective on SR-ADL function.

907

908 For active goal-targeted rehabilitation, the KOOS-pain questions could be used as a starting

909 point for clinical examination and therapy. Where the non-painful activities can be

910 emphasized to build confidence for and increase their everyday volume. Whereas the painful

911 activities can be used as rehabilitation targets to induce new movement strategies into, and or

912 progress them as loading activities in a frame of training, that challenges how clients think

913 about, physically perform, and emotionally-and-physiological respond to them, followed by

914 educating individuals to de-dramatize the act of loading with some pain (184-186), explaining

915 the discordance between radiological KOA findings and pain (187-189), reinforcing loading

916 beliefs with evidence that such does not damage the cartilage (190), teaching relaxed state-of-

917 mind, respiration, and muscle activation, as well as extinction of safety behavior during such

918 activities $(173,180)$, and further add KOA biomechanical mechanism-targeting strengthening 
919

920

921

922

923

924

925

926

927

928

929

930

931

932 [The interested clinical researcher will find further exploratory discussion on potential

933 applications of the current latent clinical prediction model in the e-appendix. Further, relevant

934 research hypotheses are suggested in an hopefully upcoming $\mathrm{PhD}$ thesis (193)].

\section{Conclusions}

937 In conclusion, the current cross-sectional study indicates potential important potential

938 predictions (i.e. independent relations) of hip rotator and ankle invertor-evertor muscle

939 strength, in addition to such of KOOS-pain and Örebro psychosocial difficulties, on self-

940 reported ADL function. That is, for patients aged 45 to 70 with small-to-moderate

941 symptomatic and radiographic KOA in primary/secondary care. The current muscle-strength

942 factors, when modelled individually with KOOS-pain and Örebro psychosocial difficulties to 
943 cover important domains of the biopsychosocial ICF-model, potentially explain a substantial

944 proportion of the variance in SR-ADL function (74\% to $78 \%$ ). Future confirmative

945 multivariable prediction model (observational) studies of biopsychosocial mechanisms and

946 management are needed to challenge these exploratory findings. RCTs are suggested to add

947 earlier promising strength exercise programs $(141,170)$, which likely targets the current

948 muscles (by proper doses per muscle-group, session, and week) and trigger key

949 biomechanical mechanisms, onto a holistic multivariable approach that targets at least pain-

950 and-disability and psychosocial factors, e.g. Cognitive functional therapy $(173,180)$.

951

952

953

\section{List of abbreviations}

954 ACR $=$ American College of Rheumatology; ACSM $=$ The American College of Sports

955 Medicine; $\mathrm{AX} 3=\mathrm{An}$ three axis accelerometer or sensor for measuring activity levels; $\mathrm{BMI}=$

956 Body mass index; CFT $=$ Cognitive functional therapy; EKADM $=$ external knee adduction

957 moment; EULAR = the European League Against Rheumatism; EUROHIS-QoL $=$ The

958 European Health Interview Survey-Quality of Life 8-item index, a questionnaire; FUNKART

$959=$ Function with knee osteoarthritis study; GPs $=$ General physicians; HHD $=$ Hand-Held

960 muscle tester Dynamometer; ICC = Intra-class correlation coefficient, a measure of reliability;

961 ICF $=$ International Classification of Function, Disability, and Health (WHO's system-based

962 clinical framework for classification of human function); K/L-grade $=$ Kellgren-Lawrence

963 grade of radiographic osteoarthritis; KOA = Knee osteoarthritis; KOOS = Knee Injury and

964 Osteoarthritis Outcome Score, a questionnaire or standardized measurement instrument; NIST

$965=$ the National Institute of Standards and Technology; NPRS = Numeric Pain Rating Scale;

966 OA = Osteoarthritis; OMSPQ-10 = Örebro Musculoskeletal Pain Screening Questionnaire 10- 
967 items; $p=$ the $p$-value is the probability value in null hypothesis significance testing, i.e., the 968 probability of obtaining test results at least as extreme as the results actually observed, under

969 the assumption that the null hypothesis is true; PROBAST $=$ Prediction model Risk Of Bias

970 ASsessment Tool; $\mathrm{R}^{2}=$ Statistical measure that represents the proportion of the variance for a

971 dependent variable that's explained by an independent variable or variables in

972 a regression model; RCTs $=$ Randomized controlled trials (most often of therapeutic

973 interventions versus active therapy, placebo therapy, or a wait-and-see control condition); RM

$974=$ Repetition maximum, the maximum number of exercise repetitions one can execute with a

975 certain weight and or body mass; SR-ADL = Self-reported activities of daily life function, a

976 subscale of KOOS; TSK-13 = Tampa Scale of Kinesiophobia, a questionnaire about fear of

977 movement/re-injury; WOMAC-PF = the Western Ontario and McMaster Universities

978 Arthritis Index Physical Function, a subscale of the WOMAC questionnaire or measurement 979 tool; Örebro = Örebro Musculoskeletal Pain Questionnaire; $\sim$ the symbol means approximate 980 or circa; $10 \mathrm{StUpDwSCT}=10$-step up-and-down stair-climb test; $1 \mathrm{RM}=1$ repetition

981 maximum in a strength test; $6 \mathrm{MWT}=$ The 6-minute walk test, a physical capability test often 982 executed in physical therapy clinics.

983

984 Declarations

985

986

\section{Acknowledgements}

987 We thank our participants for time and effort, our scientific-assistants, Erik Borg Kolsung and 988 Anja Liljegren, for co-developing and implementing the Biodex protocol and test-assistance, 989 our student-assistant Tina Marlen Bråten Mella for the latter, our training- and testing-expert

990 Dale Reese for Biodex training, and Professor Karin Roeleveld for support with analysis of 
991 Biodex data. We also thank the primary care physiotherapists Anita Bones and Bjørg Vada for 992 critics on the project proposal.

993

994

995

996

997

998

999

1000

1001

1002

1003

1004

1005

1006

1007

1008

1009

1010

1011

1012

1013

\section{Authors' contributions}

All authors substantially revised the manuscript versions for clinical and scientific content and approved the submitted version in the present form (as well as the versions leading up to it). Further, all authors have agreed to be personally accountable for the author's own contributions and to ensure that questions related to the accuracy or integrity of any part of the work, even ones in which the author was not personally involved, are appropriately investigated, resolved, and the resolution publicly documented. KV, AKS, and KGN have substantially contributed to the conception and design of the work. I.e., AKS secured funding for the project, KV wrote the research proposal update, ethical application, and protocol, and KGN substantially revised these documents together with AKS. KV and ME extensively recruited participants and collected data. KV and HL substantially analyzed and interpreted data. KV drafted and redrafted all manuscript versions before and between rounds of revisions. KV is the guarantor of the manuscript's authenticity.

\section{Funding}

This work was supported by the former Sor-Trondelag University College. The funding was granted to A. K. Stensdotter, the head of the PhD-project entitled "Mechanisms for improved physical function with knee osteoarthritis". There exists no grant number. The funders had no role in study design, data collection and analysis, decision to publish, or in writing the manuscript. 
1015 The FUNKART study was approved by a Regional Ethics Committee for Medical and Health

1016 Research (the Regional Ethics Committee North, REC-north 2016/984 [In Norwegian REK-nord])

1017 and conducted according to the Helsinki declaration and Norwegian laws. The participants

1018 signed the approved written consent before participation.

1019

1020 Consent for publication

1021 Not applicable.

1022

1023 Availability of data and material

1024 The dataset generated and analyzed during the current study are available on reasonable

1025 request from the head of the project AKS or from the Department of Neuroscience and

1026 Movement Science, Faculty of Medicine and Health Science, Norwegian University of

1027 Science and Technology.

1028

\section{Competing interests}

1030 The authors declare that they have no competing interests regarding the present study.

1031

1032

Trial registration

1033 Not applicable. 
1036 1. Vaarbakken K, Loras H, Nilsson KG, Engdal M, Stensdotter AK. Relative difference

1037

1038

1039

1040

1041

1042

1043

1044

1045

1046

1047

1048

1049

1050

1051

1052

1053

1054

1055

1056

1057

1058

1059

1060

1061

1062

1063

1064

1065

1066

1067

1068

1069

1070

1071

1072

1073

1074

1075

1076

1077

1078

1079

1080 among 27 functional measures in patients with knee osteoarthritis: An exploratory crosssectional case-control study. BMC musculoskeletal disorders. 2019; In press.

2. Vaarbakken K, Loras H, Nilsson KG, Engdal M, Stensdotter AK. Relative difference in muscle strength between patients with knee osteoarthritis and healthy controls when tested bilaterally and joint-inclusive: An exploratory cross-sectional study. BMC musculoskeletal disorders. 2019; In press.

3. Sharif B, Garner R, Hennessy D, Sanmartin C, Flanagan WM, Marshall DA. Productivity costs of work loss associated with osteoarthritis in Canada from 2010 to 2031. Osteoarthritis Cartilage. 2017;25(2):249-58.

4. Le Pen C, Reygrobellet C, Gerentes I. Financial cost of osteoarthritis in France. The "COART" France study. Joint, bone, spine : revue du rhumatisme. 2005;72(6):567-70.

5. Kingsbury SR, Gross HJ, Isherwood G, Conaghan PG. Osteoarthritis in Europe: impact on health status, work productivity and use of pharmacotherapies in five European countries. Rheumatology (Oxford, England). 2014;53(5):937-47.

6. Hermans J, Koopmanschap MA, Bierma-Zeinstra SM, van Linge JH, Verhaar JA, Reijman M, et al. Productivity costs and medical costs among working patients with knee osteoarthritis. Arthritis care \& research. 2012;64(6):853-61.

7. March L, Smith EU, Hoy DG, Cross MJ, Sanchez-Riera L, Blyth F, et al. Burden of disability due to musculoskeletal (MSK) disorders. Best practice \& research Clinical rheumatology. 2014;28(3):353-66.

8. Turkiewicz A, Gerhardsson de Verdier M, Engstrom G, Nilsson PM, Mellstrom C, Lohmander LS, et al. Prevalence of knee pain and knee OA in southern Sweden and the proportion that seeks medical care. Rheumatology (Oxford, England). 2015;54(5):827-35. 9. Zhang W, Doherty M, Peat G, Bierma-Zeinstra MA, Arden NK, Bresnihan B, et al. EULAR evidence-based recommendations for the diagnosis of knee osteoarthritis. Annals of the rheumatic diseases. 2010;69(3):483-9.

10. Altman RD. Criteria for the classification of osteoarthritis of the knee and hip. ScandJRheumatolSuppl. 1987;65:31-9.

11. Oliveria SA, Felson DT, Reed JI, Cirillo PA, Walker AM. Incidence of symptomatic hand, hip, and knee osteoarthritis among patients in a health maintenance organization. Arthritis Rheum. 1995;38(8):1134-41.

12. de Zwart AH, Dekker J, Lems W, Roorda LD, van der Esch M, van der Leeden M. Factors associated with upper leg muscle strength in knee osteoarthritis: A scoping review. Journal of rehabilitation medicine. 2018;50(2):140-50.

13. Raastad T, Paulsen G, Refsnes PE, Rønnestad BR, Wisnes A. Strength exercise - in theory and praxis. 1th ed. Oslo: Gyldendal Norsk Forlag AS; 20102010.

14. Komi PV, Dirix A, Knuttgen HG, Tittel K, International Olympic C. The Encyclopaedia of sports medicine : an International Olympic Committee publication ; in collaboration with the International Federation of Sports Medicine : Vol. 3 : Strength and power in sport. 2nd ed. ed. Oxford: Blackwell; 2003.

15. Knuttgen HG, Kraemer WJ. Terminology and measurement in exercise performance. J Appl Sport Sci Res. 1987;1(1):10.

16. American College of Sports Medicine position stand. Progression models in resistance training for healthy adults. Medicine and science in sports and exercise. 2009;41(3):687-708. 
1081 17. Schoenfeld BJ, Grgic J. Effects of range of motion on muscle development during

1082

1083

1084

1085

1086

1087

1088

1089

1090

1091

1092

1093

1094

1095

1096

1097

1098

1099

1100

1101

1102

1103

1104

1105

1106

1107

1108

1109

1110

1111

1112

1113

1114

1115

1116

1117

1118

1119

1120

1121

1122

1123

1124

1125

1126

1127

1128

1129

resistance training interventions: A systematic review. SAGE Open Med. 2020;8:2050312120901559.

18. Hopkins WG. A Scale of Magnitudes for Effect Statistics 2002 [Available from: http://www.sportsci.org/resource/stats/effectmag.html

19. Deasy M, Leahy E, Semciw AI. Hip Strength Deficits in People With Symptomatic Knee Osteoarthritis: A Systematic Review With Meta-analysis. The Journal of orthopaedic and sports physical therapy. 2016;46(8):629-39.

20. van Tunen JAC, Dell'Isola A, Juhl C, Dekker J, Steultjens M, Thorlund JB, et al. Association of malalignment, muscular dysfunction, proprioception, laxity and abnormal joint loading with tibiofemoral knee osteoarthritis - a systematic review and meta-analysis. BMC musculoskeletal disorders. 2018;19(1):273.

21. Culvenor AG, Ruhdorfer A, Juhl C, Eckstein F, Oiestad BE. Knee Extensor Strength and Risk of Structural, Symptomatic, and Functional Decline in Knee Osteoarthritis: A Systematic Review and Meta-Analysis. Arthritis care \& research. 2017;69(5):649-58.

22. Oiestad BE, Juhl CB, Eitzen I, Thorlund JB. Knee extensor muscle weakness is a risk factor for development of knee osteoarthritis. A systematic review and meta-analysis. Osteoarthritis Cartilage. 2015;23(2):171-7.

23. Bartholdy C, Juhl C, Christensen R, Lund H, Zhang W, Henriksen M. The role of muscle strengthening in exercise therapy for knee osteoarthritis: A systematic review and meta-regression analysis of randomized trials. Seminars in arthritis and rheumatism. 2017;47(1):9-21.

24. Fransen M, McConnell S, Harmer AR, Van der Esch M, Simic M, Bennell KL. Exercise for osteoarthritis of the knee: a Cochrane systematic review. British journal of sports medicine. 2015;49(24):1554-7.

25. Brosseau L, Taki J, Desjardins B, Thevenot O, Fransen M, Wells GA, et al. The Ottawa panel clinical practice guidelines for the management of knee osteoarthritis. Part two: strengthening exercise programs. Clinical rehabilitation. 2017;31(5):596-611.

26. Hislop AC, Collins NJ, Tucker K, Deasy M, Semciw AI. Does adding hip exercises to quadriceps exercises result in superior outcomes in pain, function and quality of life for people with knee osteoarthritis? A systematic review and meta-analysis. British journal of sports medicine. 2019.

27. Ashok C. Effects of hip abductor muscle strengthening exercises in patients with osteoarthritic knee joints. Indian Journal of Physiotherapy \& Occupational Therapy. 2012;6:5. 28. Varbakken K, Loras H, Nilsson KG, Engdal M, Stensdotter AK. Relative difference in muscle strength between patients with knee osteoarthritis and healthy controls when tested bilaterally and joint-inclusive: an exploratory cross-sectional study. BMC musculoskeletal disorders. 2019;20(1):593.

29. WHO. ICF - International classification of functioning, disability and health. Geneva, Switzerland: World Health Organization; 2001.

30. Westman A, Linton SJ, Ohrvik J, Wahlen P, Leppert J. Do psychosocial factors predict disability and health at a 3-year follow-up for patients with non-acute musculoskeletal pain? A validation of the Orebro Musculoskeletal Pain Screening Questionnaire. European journal of pain (London, England). 2008;12(5):641-9.

31. Panken G, Verhagen AP, Terwee CB, Heymans MW. Clinical Prediction Models for Patients With Nontraumatic Knee Pain in Primary Care: A Systematic Review and Internal Validation Study. The Journal of orthopaedic and sports physical therapy. 2017;47(8):518-29. 32. Rolfson O, Wissig S, van Maasakkers L, Stowell C, Ackerman I, Ayers D, et al. Defining an International Standard Set of Outcome Measures for Patients With Hip or Knee 
1130 Osteoarthritis: Consensus of the International Consortium for Health Outcomes Measurement

1131 Hip and Knee Osteoarthritis Working Group. Arthritis care \& research. 2016;68(11):1631-9.

1132 33. Brunner R, Friesenbichler B, Casartelli NC, Bizzini M, Maffiuletti NA, Niedermann

1133 K. Effectiveness of multicomponent lower extremity injury prevention programmes in team-

1134

1135

1136

1137

1138

1139

1140

1141

1142

1143

1144

1145

1146

1147 sport athletes: an umbrella review. British journal of sports medicine. 2019;53(5):282-8.

34. Hanlon C, Krzak JJ, Prodoehl J, Hall KD. Effect of Injury Prevention Programs on Lower Extremity Performance in Youth Athletes: A Systematic Review. Sports Health. 2020;12(1):12-22.

35. Rothman KJ, Greenland S, Poole C, Lash TL. Causation and causal inference. In: Rothman KJ, Greenland S, Lash TL, editors. Modern epidemiology. 3rd ed. London: Wolters Kluwer | Lippincott Williams \& Wilkins; 2008. p. 5-31.

36. Bastick AN, Runhaar J, Belo JN, Bierma-Zeinstra SM. Prognostic factors for progression of clinical osteoarthritis of the knee: a systematic review of observational studies. Arthritis research \& therapy. 2015;17:152.

37. Goh SL, Persson MSM, Stocks J, Hou Y, Welton NJ, Lin J, et al. Relative Efficacy of Different Exercises for Pain, Function, Performance and Quality of Life in Knee and Hip Osteoarthritis: Systematic Review and Network Meta-Analysis. Sports medicine (Auckland, NZ). 2019.

1148

1149 38. Althouse AD. Adjust for Multiple Comparisons? It's Not That Simple. Ann Thorac Surg. 2016;101(5):1644-5.

1150 39. Bender R, Lange S. Adjusting for multiple testing--when and how? Journal of clinical epidemiology. 2001;54(4):343-9.

40. Varbakken K, Loras H, Nilsson KG, Engdal M, Stensdotter AK. Relative difference among 27 functional measures in patients with knee osteoarthritis: an exploratory crosssectional case-control study. BMC musculoskeletal disorders. 2019;20(1):462.

41. Field A. Discovering statistics using IBM SPSS statistics : and sex and drugs and rock 'n' roll. 4th ed. ed. Los Angeles: SAGE; 2013.

42. Rosner B. Fundamentals of biostatistics. 8th ed. ed. Boston, Mass: Cengage Learning; 2016.

43. Rothman KJ. No adjustments are needed for multiple comparisons. Epidemiology. 1990;1(1):43-6.

44. Rothman KJ, Greenland S, Lash TL, Buehler JW, Cahill J, Glymour MM, et al. Modern epidemiology. 3rd ed. ed. Philadelphia: Wolters Kluwer/Lippincott Williams \& Wilkins; 2008.

45. Nelder J. From statistics to statistical science - Reply. J R Stat Soc Ser D-Stat. 1999;48:269-.

46. Perneger TV. What's wrong with Bonferroni adjustments. Bmj. 1998;316(7139):12368.

47. Syltebo R, Odegaard TT. InfoPad AS 2012 [Available from: https://infopad.no/

1170

1171

1172

1173

1174

1175 48. Kellgen JH, Lawrence JS. Radiological assessment of osteo-arthrosis. AnnRheumDis. 1957;16(4):494-502.

49. Wolfe F, Smythe HA, Yunus MB, Bennett RM, Bombardier C, Goldenberg DL, et al. The American College of Rheumatology 1990 Criteria for the Classification of Fibromyalgia. Report of the Multicenter Criteria Committee. Arthritis Rheum. 1990;33(2):160-72. 50. Mansfield KE, Sim J, Croft P, Jordan KP. Identifying patients with chronic widespread pain in primary care. Pain. 2017;158(1):110-9. 51. Horsak B, Pobatschnig B, Baca A, Greber-Platzer S, Kreissl A, Nehrer S, et al. Within-assessor reliability and minimal detectable change of gait kinematics in a young obese demographic. Gait Posture. 2017;54:112-8. 
1179 52. de Araujo Ribeiro Alvares JB, Rodrigues R, de Azevedo Franke R, da Silva BG, Pinto

1180 RS, Vaz MA, et al. Inter-machine reliability of the Biodex and Cybex isokinetic

1181 dynamometers for knee flexor/extensor isometric, concentric and eccentric tests. Physical

1182 therapy in sport : official journal of the Association of Chartered Physiotherapists in Sports

1183 Medicine. 2015;16(1):59-65.

1184 53. Hartmann A, Knols R, Murer K, de Bruin ED. Reproducibility of an isokinetic

1185

1186 strength-testing protocol of the knee and ankle in older adults. Gerontology. 2009;55(3):25968.

54. Biodex. Biodex Multi-Joint System - Pro Setup/Operation Manual Biodex Medical Systems Inc.; 2014 [Available from:

1189 http://www.biodex.com/sites/default/files/850000man 08262revb.pdf.

1190 55. Baldon RM, Nakagawa TH, Muniz TB, Amorim CF, Maciel CD, Serrao FV. Eccentric 2009;44(5):490-6.

56. Thorborg K, Bandholm T, Holmich P. Hip- and knee-strength assessments using a hand-held dynamometer with external belt-fixation are inter-tester reliable. KneeSurgSports TraumatolArthrosc. 2013;21(3):550-5.

57. Vaarbakken K, Ljunggren AE. Superior effect of forceful compared to standard traction mobilization in hip disability? Advances in Physiotherapy. 2007;9(3):117-28. 58. Sanchez-Ramirez DC, van der Leeden M, Knol DL, van der Esch M, Roorda LD, Verschueren S, et al. Association of postural control with muscle strength, proprioception, self-reported knee instability and activity limitations in patients with knee osteoarthritis. Journal of rehabilitation medicine. 2013;45(2):192-7. 59. Federation IW. IWF Guidelines Sports Equipment Licensing. https://www.iwf.net/wpcontent/uploads/downloads/2015/11/IWF-Guidelines_Sport-Equipment-Licensing.pdf: International Weightlifting Federation; 2019. p. 19.

60. Roos EM, Roos HP, Lohmander LS, Ekdahl C, Beynnon BD. Knee Injury and Osteoarthritis Outcome Score (KOOS)--development of a self-administered outcome measure. The Journal of orthopaedic and sports physical therapy. 1998;28(2):88-96. 61. Roos EM, Lohmander LS. The Knee injury and Osteoarthritis Outcome Score (KOOS): from joint injury to osteoarthritis. Health and quality of life outcomes. 2003;1:64. 62. McAlindon TE, Bannuru RR, Sullivan MC, Arden NK, Berenbaum F, BiermaZeinstra SM, et al. OARSI guidelines for the non-surgical management of knee osteoarthritis. Osteoarthritis Cartilage. 2014;22(3):363-88.

63. AbilityLab SR. Rehabilitation Measures Database 2018 [Available from: https://www.sralab.org/rehabilitation-measures 64. Collins NJ, Prinsen CA, Christensen R, Bartels EM, Terwee CB, Roos EM. Knee Injury and Osteoarthritis Outcome Score (KOOS): systematic review and meta-analysis of measurement properties. Osteoarthritis Cartilage. 2016.

65. Linton SJ, Nicholas M, MacDonald S. Development of a short form of the Orebro Musculoskeletal Pain Screening Questionnaire. Spine (Phila Pa 1976). 2011;36(22):1891-5. 66. Goldsmith ES, Taylor BC, Greer N, Murdoch M, MacDonald R, McKenzie L, et al. Focused Evidence Review: Psychometric Properties of Patient-Reported Outcome Measures for Chronic Musculoskeletal Pain. Journal of general internal medicine. 2018;33(Suppl 1):6170.

67. Neblett R, Hartzell MM, Mayer TG, Bradford EM, Gatchel RJ. Establishing clinically meaningful severity levels for the Tampa Scale for Kinesiophobia (TSK-13). European journal of pain (London, England). 2016;20(5):701-10. 68. Feng Y, Wong CK, Janeja V, Kuber R, Mentis HM. Comparison of tri-axial accelerometers step-count accuracy in slow walking conditions. Gait Posture. 2017;53:11-6. 
69. Stewart T, Narayanan A, Hedayatrad L, Neville J, Mackay L, Duncan S. A DualAccelerometer System for Classifying Physical Activity in Children and Adults. Medicine and science in sports and exercise. 2018.

70. Tveter AT, Dagfinrud H, Moseng T, Holm I. Measuring health-related physical fitness in physiotherapy practice: reliability, validity, and feasibility of clinical field tests and a patient-reported measure. The Journal of orthopaedic and sports physical therapy. 2014;44(3):206-16.

71. Schmidt S, Muhlan H, Power M. The EUROHIS-QOL 8-item index: psychometric results of a cross-cultural field study. European journal of public health. 2006;16(4):420-8. 72. Linton SJ, Hallden K. Can we screen for problematic back pain? A screening questionnaire for predicting outcome in acute and subacute back pain. The Clinical journal of pain. 1998;14(3):209-15.

73. Linton SJ, Boersma K. Early identification of patients at risk of developing a persistent back problem: the predictive validity of the Orebro Musculoskeletal Pain Questionnaire. The Clinical journal of pain. 2003;19(2):80-6.

74. Hockings RL, McAuley JH, Maher CG. A systematic review of the predictive ability of the Orebro Musculoskeletal Pain Questionnaire. Spine (Phila Pa 1976). 2008;33(15):E494500 .

75. Duncan S, Stewart T, Mackay L, Neville J, Narayanan A, Walker C, et al. Wear-Time Compliance with a Dual-Accelerometer System for Capturing 24-h Behavioural Profiles in Children and Adults. International journal of environmental research and public health. 2018;15(7).

76. Brosseau L, Taki J, Desjardins B, Thevenot O, Fransen M, Wells GA, et al. The Ottawa panel clinical practice guidelines for the management of knee osteoarthritis. Part one: introduction, and mind-body exercise programs. Clinical rehabilitation. 2017;31(5):582-95. 77. Brosseau L, Taki J, Desjardins B, Thevenot O, Fransen M, Wells GA, et al. The Ottawa panel clinical practice guidelines for the management of knee osteoarthritis. Part three: aerobic exercise programs. Clinical rehabilitation. 2017;31(5):612-24.

78. Faul F, Erdfelder E, Buchner A, Lang AG. Statistical power analyses using G*Power 3.1: tests for correlation and regression analyses. Behavior research methods. 2009;41(4):1149-60.

79. Faul F, Erdfelder E, Lang AG, Buchner A. G*Power 3: a flexible statistical power analysis program for the social, behavioral, and biomedical sciences. Behavior research methods. 2007;39(2):175-91.

80. Buchner A, Erdfelder E, Faul F, Lang AG. G*Power: Statistical Power Analyses for Windows and Mac Website: Heinrich Heine Universität Düsseldorf 2019 [Available from: http://www.psychologie.hhu.de/arbeitsgruppen/allgemeine-psychologie-undarbeitspsychologie/gpower.html.

81. Cohen J. Statistical power analysis for the behavioral sciences. Hillsdale, N.J.: Lawrence Erlbaum Associates; 19881988.

82. Hayes AF. Introduction to mediation, moderation, and conditional process analysis Little TD, editor. New York: The Guilford Press; 2018. 692 p.

83. Mukaka MM. Statistics corner: A guide to appropriate use of correlation coefficient in medical research. Malawi medical journal : the journal of Medical Association of Malawi. 2012;24(3):69-71.

84. Royston P, Moons KG, Altman DG, Vergouwe Y. Prognosis and prognostic research: Developing a prognostic model. Bmj. 2009;338:b604.

85. Neelapala YVR, Bhagat M, Shah P. Hip Muscle Strengthening for Knee Osteoarthritis: A Systematic Review of Literature. Journal of geriatric physical therapy (2001). 2018. 
86. Textor J, Hardt J, Knuppel S. DAGitty: a graphical tool for analyzing causal diagrams. Epidemiology (Cambridge, Mass). 2011;22(5):745.

87. Textor J, van der Zander B, Gilthorpe MS, Liskiewicz M, Ellison GT. Robust causal inference using directed acyclic graphs: the R package 'dagitty'. Int J Epidemiol. 2016;45(6):1887-94.

88. Williamson EJ, Aitken Z, Lawrie J, Dharmage SC, Burgess JA, Forbes AB. Introduction to causal diagrams for confounder selection. Respirology. 2014;19(3):303-11. 89. Greenland S, Pearl J, Robins JM. Causal diagrams for epidemiologic research. Epidemiology. 1999;10(1):37-48.

90. Hernan MA, Hernandez-Diaz S, Werler MM, Mitchell AA. Causal knowledge as a prerequisite for confounding evaluation: an application to birth defects epidemiology. Am J Epidemiol. 2002;155(2):176-84. 91. Chang AH, Chmiel JS, Almagor O, Hayes KW, Guermazi A, Prasad PV, et al. Hip muscle strength and protection against structural worsening and poor function and disability outcomes in knee osteoarthritis. Osteoarthritis Cartilage. 2019;27(6):885-94.

92. Porta MS. A Dictionary of Epidemiology. Oxford: Oxford University Press; 2014. 93. Clinical Guidelines on the Identification, Evaluation, and Treatment of Overweight and Obesity in Adults--The Evidence Report. National Institutes of Health. Obesity research. 1998;6 Suppl 2:51s-209s.

94. Executive summary: Guidelines (2013) for the management of overweight and obesity in adults: a report of the American College of Cardiology/American Heart Association Task Force on Practice Guidelines and the Obesity Society published by the Obesity Society and American College of Cardiology/American Heart Association Task Force on Practice Guidelines. Based on a systematic review from the The Obesity Expert Panel, 2013. Obesity (Silver Spring, Md). 2014;22 Suppl 2:S5-39.

95. Hochberg MC, Altman RD, April KT, Benkhalti M, Guyatt G, McGowan J, et al. American College of Rheumatology 2012 recommendations for the use of nonpharmacologic and pharmacologic therapies in osteoarthritis of the hand, hip, and knee. Arthritis care \& research. 2012;64(4):465-74.

96. Surgeons TAAoO. Treatment of osteoarthritis of the knee - evidence based guideline Online: The American Academy of Orthopaedic Surgeons; 2013 [2nd:[Available from: http://www.aaos.org/cc files/aaosorg/research/guidelines/treatmentofosteoarthritisofthekneeg uideline.pdf.

\section{Peter WF, Jansen MJ, Hurkmans EJ, Bloo H, Dekker J, Dilling RG, et al.}

Physiotherapy in hip and knee osteoarthritis: development of a practice guideline concerning initial assessment, treatment and evaluation. Acta reumatologica portuguesa. 2011;36(3):26881.

98. Fitzgerald GK, Hinman RS, Zeni J, Jr., Risberg MA, Snyder-Mackler L, Bennell KL. OARSI Clinical Trials Recommendations: Design and conduct of clinical trials of rehabilitation interventions for osteoarthritis. Osteoarthritis Cartilage. 2015;23(5):803-14. 99. Fernandes L, Hagen KB, Bijlsma JW, Andreassen O, Christensen P, Conaghan PG, et al. EULAR recommendations for the non-pharmacological core management of hip and knee osteoarthritis. Annals of the rheumatic diseases. 2013;72(7):1125-35.

100. Hill AB. THE ENVIRONMENT AND DISEASE: ASSOCIATION OR CAUSATION? Proceedings of the Royal Society of Medicine. 1965;58:295-300. 101. VanderWeele TJ. Explanation in causal inference: developments in mediation and interaction. Int J Epidemiol. 2016;45(6):1904-8.

102. Hayes AF, Rockwood NJ. Regression-based statistical mediation and moderation analysis in clinical research: Observations, recommendations, and implementation. Behav Res Ther. 2017;98:39-57. 
103. Riley RD, Moons KGM, Snell KIE, Ensor J, Hooft L, Altman DG, et al. A guide to systematic review and meta-analysis of prognostic factor studies. Bmj. 2019;364:k4597. 104. Riley RD, Jackson D, Salanti G, Burke DL, Price M, Kirkham J, et al. Multivariate and network meta-analysis of multiple outcomes and multiple treatments: rationale, concepts, and examples. Bmj. 2017;358:j3932.

105. Moons KGM, Wolff RF, Riley RD, Whiting PF, Westwood M, Collins GS, et al. PROBAST: A Tool to Assess Risk of Bias and Applicability of Prediction Model Studies: Explanation and Elaboration. Annals of internal medicine. 2019;170(1):W1-w33.

106. Schisterman EF, Cole SR, Platt RW. Overadjustment bias and unnecessary adjustment in epidemiologic studies. Epidemiology. 2009;20(4):488-95.

107. VanderWeele TJ. On the relative nature of overadjustment and unnecessary adjustment. Epidemiology. 2009;20(4):496-9.

108. Green MJ, Popham F. Interpreting mutual adjustment for multiple indicators of socioeconomic position without committing mutual adjustment fallacies. BMC public health. 2019;19(1):10.

109. Hernan MA, Robins JM. Per-Protocol Analyses of Pragmatic Trials. The New England journal of medicine. 2017;377(14):1391-8.

110. Calders P, Van Ginckel A. Presence of comorbidities and prognosis of clinical symptoms in knee and/or hip osteoarthritis: A systematic review and meta-analysis. Seminars in arthritis and rheumatism. 2018;47(6):805-13.

111. Furlan AD, Malmivaara A, Chou R, Maher CG, Deyo RA, Schoene M, et al. 2015 Updated Method Guideline for Systematic Reviews in the Cochrane Back and Neck Group. Spine (Phila Pa 1976). 2015;40(21):1660-73.

112. van der Esch M, Knoop J, van der Leeden M, Voorneman R, Gerritsen M, Reiding D, et al. Self-reported knee instability and activity limitations in patients with knee osteoarthritis: results of the Amsterdam osteoarthritis cohort. Clinical rheumatology. 2012;31(10):1505-10. 113. Collins GS, Reitsma JB, Altman DG, Moons KG. Transparent Reporting of a multivariable prediction model for Individual Prognosis Or Diagnosis (TRIPOD). Annals of internal medicine. 2015;162(10):735-6.

114. Debray TP, Damen JA, Riley RD, Snell K, Reitsma JB, Hooft L, et al. A framework for meta-analysis of prediction model studies with binary and time-to-event outcomes. Stat Methods Med Res. 2019;28(9):2768-86.

115. Wolff RF, Moons KGM, Riley RD, Whiting PF, Westwood M, Collins GS, et al. PROBAST: A Tool to Assess the Risk of Bias and Applicability of Prediction Model Studies. Annals of internal medicine. 2019;170(1):51-8.

116. Kleinbaum DG. Applied regression analysis and multivariable methods. Belmont, Calif.: Thomson; 2008.

117. Colbert CJ, Song J, Dunlop D, Chmiel JS, Hayes KW, Cahue S, et al. Knee confidence as it relates to physical function outcome in persons with or at high risk of knee osteoarthritis in the osteoarthritis initiative. Arthritis and rheumatism. 2012;64(5):1437-46.

118. Sharma L, Cahue S, Song J, Hayes K, Pai YC, Dunlop D. Physical functioning over three years in knee osteoarthritis: role of psychosocial, local mechanical, and neuromuscular factors. Arthritis and rheumatism. 2003;48(12):3359-70.

119. Thomas E, Peat G, Mallen C, Wood L, Lacey R, Duncan R, et al. Predicting the course of functional limitation among older adults with knee pain: do local signs, symptoms and radiographs add anything to general indicators? Annals of the rheumatic diseases. 2008;67(10):1390-8.

120. White DK, Zhang Y, Niu J, Keysor JJ, Nevitt MC, Lewis CE, et al. Do worsening knee radiographs mean greater chances of severe functional limitation? Arthritis care \& research. 2010;62(10):1433-9. 
121. Amin S, Baker K, Niu J, Clancy M, Goggins J, Guermazi A, et al. Quadriceps strength and the risk of cartilage loss and symptom progression in knee osteoarthritis. Arthritis and rheumatism. 2009;60(1):189-98.

\section{Pisters MF, Veenhof C, van Dijk GM, Heymans MW, Twisk JW, Dekker J. The} course of limitations in activities over 5 years in patients with knee and hip osteoarthritis with moderate functional limitations: risk factors for future functional decline. Osteoarthritis Cartilage. 2012;20(6):503-10.

123. Hislop AC, Collins NJ, Tucker K, Deasy M, Semciw AI. Does adding hip exercises to quadriceps exercises result in superior outcomes in pain, function and quality of life for people with knee osteoarthritis? A systematic review and meta-analysis. British journal of sports medicine. 2020;54(5):263-71.

124. Bennell KL, Kyriakides M, Metcalf B, Egerton T, Wrigley TV, Hodges PW, et al. Neuromuscular versus quadriceps strengthening exercise in patients with medial knee osteoarthritis and varus malalignment: a randomized controlled trial. Arthritis \& rheumatology (Hoboken, NJ). 2014;66(4):950-9.

125. Chaipinyo K, Karoonsupcharoen O. No difference between home-based strength training and home-based balance training on pain in patients with knee osteoarthritis: a randomised trial. Aust J Physiother. 2009;55(1):25-30.

126. Verma S, Agarwal S. The effect of hip abductors strengthening exercise on knee pain and function in people with knee osteoarthritis. Sports Medicine Journal / Medicina Sportivâ. 2013;9:6.

127. Singh S, Pattnaik M, Mohanty P, Ganesh GS. Effectiveness of hip abductor strengthening on health status, strength, endurance and six minute walk test in participants with medial compartment symptomatic knee osteoarthritis. Journal of back and musculoskeletal rehabilitation. 2016;29(1):65-75.

128. Neumann DA, Kelly ER, Kiefer C. Kinesiology of the musculoskeletal system : foundations for rehabilitation. St. Louis, Mo.: Elsevier; 2017.

129. Vaarbakken K, Steen H, Samuelsen G, Dahl HA, Leergaard TB, Nordsletten L, et al. Lengths of the external hip rotators in mobilized cadavers indicate the quadriceps coxa as a primary abductor and extensor of the flexed hip. Clin Biomech. 2014;29(7):794-802.

130. Stern JTJ, Larson SG. Electromyographic study of the obturator muscles in nonhuman Primates: implications for interpreting the obturator externus groove of the femur. Journal of Human Evolution. 1993;24(5):403-27. 131. Neumann DA. Kinesiology of the hip: a focus on muscular actions. JOrthopSports PhysTher. 2010;40(2):82-94.

132. Oranchuk DJ, Storey AG, Nelson AR, Cronin JB. Isometric training and long-term adaptations: Effects of muscle length, intensity, and intent: A systematic review.

Scandinavian journal of medicine \& science in sports. 2019;29(4):484-503.

133. Farrokhi S, Voycheck CA, Gustafson JA, Fitzgerald GK, Tashman S. Knee joint contact mechanics during downhill gait and its relationship with varus/valgus motion and muscle strength in patients with knee osteoarthritis. The Knee. 2016;23(1):49-56. 134. Hodges PW, van den Hoorn W, Wrigley TV, Hinman RS, Bowles KA, Cicuttini F, et al. Increased duration of co-contraction of medial knee muscles is associated with greater progression of knee osteoarthritis. Man Ther. 2016;21:151-8.

135. van der Krogt MM, Delp SL, Schwartz MH. How robust is human gait to muscle weakness? Gait Posture. 2012;36(1):113-9.

136. Mills K, Hunt MA, Leigh R, Ferber R. A systematic review and meta-analysis of lower limb neuromuscular alterations associated with knee osteoarthritis during level walking. Clinical biomechanics (Bristol, Avon). 2013;28(7):713-24. 
137. van Wingerden BAM. Connective tissue in rehabilitation. Liechtenstein: Scipro Verlag-Vaduz; 19951995. 138. Servin-Vences MR, Richardson J, Lewin GR, Poole K. Mechanoelectrical transduction in chondrocytes. Clin Exp Pharmacol Physiol. 2018;45(5):481-8. 139. Ingber DE, Wang N, Stamenovic D. Tensegrity, cellular biophysics, and the mechanics of living systems. Rep Prog Phys. 2014;77(4):046603.

140. Khan KM, Scott A. Mechanotherapy: how physical therapists' prescription of exercise promotes tissue repair. BrJ Sports Med. 2009;43(4):247-52.

141. Snyder KR, Earl JE, O'Connor KM, Ebersole KT. Resistance training is accompanied by increases in hip strength and changes in lower extremity biomechanics during running. ClinBiomech(Bristol, Avon). 2009;24(1):26-34.

142. Henriksen M, Creaby MW, Lund H, Juhl C, Christensen R. Is there a causal link between knee loading and knee osteoarthritis progression? A systematic review and metaanalysis of cohort studies and randomised trials. BMJ open. 2014;4(7):e005368.

143. Bennell KL, Hunt MA, Wrigley TV, Hunter DJ, McManus FJ, Hodges PW, et al. Hip strengthening reduces symptoms but not knee load in people with medial knee osteoarthritis and varus malalignment: a randomised controlled trial. Osteoarthritis Cartilage. 2010;18(5):621-8.

144. Bennell KL, Hunt MA, Wrigley TV, Hunter DJ, Hinman RS. The effects of hip muscle strengthening on knee load, pain, and function in people with knee osteoarthritis: a protocol for a randomised, single-blind controlled trial. BMC musculoskeletal disorders. 2007;8:121.

145. Peterson MD, Rhea MR, Alvar BA. Applications of the dose-response for muscular strength development: a review of meta-analytic efficacy and reliability for designing training prescription. J Strength Cond Res. 2005;19(4):950-8.

146. Oostdam N, van Poppel MN, Eekhoff EM, Wouters MG, van Mechelen W. Design of FitFor2 study: the effects of an exercise program on insulin sensitivity and plasma glucose levels in pregnant women at high risk for gestational diabetes. BMC pregnancy and childbirth. 2009;9:1.

147. Hertling D, Kessler R. Management of common musculoskeletal disorders : physical therapy principles and methods. Philadelphia: Lippincott; 1996.

148. Ratamess NA, Alvar BA, Evetoch TK, Housh TJ, Kibler WB, Kraemer WJ, et al. American College of Sports Medicine Position Stand: Progression models in resistance training for healthy adults. Medicine and science in sports and exercise. 2009;41(3):687-708. 149. Garber CE, Blissmer B, Deschenes MR, Franklin BA, Lamonte MJ, Lee IM, et al. American College of Sports Medicine position stand. Quantity and quality of exercise for developing and maintaining cardiorespiratory, musculoskeletal, and neuromotor fitness in apparently healthy adults: guidance for prescribing exercise. Medicine and science in sports and exercise. 2011;43(7):1334-59.

150. Borde R, Hortobagyi T, Granacher U. Dose-Response Relationships of Resistance Training in Healthy Old Adults: A Systematic Review and Meta-Analysis. Sports medicine (Auckland, NZ). 2015;45(12):1693-720.

151. Young JL, Rhon DI, Cleland JA, Snodgrass SJ. The Influence of Exercise Dosing on Outcomes in Patients With Knee Disorders: A Systematic Review. The Journal of orthopaedic and sports physical therapy. 2018;48(3):146-61.

152. Nascimento LR, Teixeira-Salmela LF, Souza RB, Resende RA. Hip and Knee Strengthening Is More Effective Than Knee Strengthening Alone for Reducing Pain and Improving Activity in Individuals With Patellofemoral Pain: A Systematic Review With Meta-analysis. The Journal of orthopaedic and sports physical therapy. 2018;48(1):19-31. 
153. Khayambashi K, Mohammadkhani Z, Ghaznavi K, Lyle MA, Powers CM. The effects of isolated hip abductor and external rotator muscle strengthening on pain, health status, and hip strength in females with patellofemoral pain: a randomized controlled trial. The Journal of orthopaedic and sports physical therapy. 2012;42(1):22-9.

154. Ratamess N, American College of Sports M. ACSM's Foundations of Strength Training and Conditioning. Philadelphia, Pa.: Lippincott Williams and Wilkins; 2012. 155. Katz P, O'Grady M, Davis G, Rojas-Fernandez C, Ferrell B, Levy R, et al. Exercise prescription for older adults with osteoarthritis pain: consensus practice recommendations. A supplement to the AGS Clinical Practice Guidelines on the management of chronic pain in older adults. Journal of the American Geriatrics Society. 2001;49(6):808-23.

156. Lesinski M, Prieske O, Granacher U. Effects and dose-response relationships of resistance training on physical performance in youth athletes: a systematic review and metaanalysis. British journal of sports medicine. 2016;50(13):781-95.

157. Hoffmann TC, Glasziou PP, Boutron I, Milne R, Perera R, Moher D, et al. Better reporting of interventions: template for intervention description and replication (TIDieR) checklist and guide. Bmj. 2014;348:g1687.

158. Slade SC, Dionne CE, Underwood M, Buchbinder R. Consensus on Exercise Reporting Template (CERT): Explanation and Elaboration Statement. British journal of sports medicine. 2016;50(23):1428-37.

159. Bartholdy C, Nielsen SM, Warming S, Hunter DJ, Christensen R, Henriksen M. Poor replicability of recommended exercise interventions for knee osteoarthritis: a descriptive analysis of evidence informing current guidelines and recommendations. Osteoarthritis Cartilage. 2019;27(1):3-22.

160. Haff GG, Triplett NT. Essentials of Strength Training and Conditioning/National Strength and Conditioning Association. Champaign, IL, USA: Human Kinetics, Inc.; 2016. 161. Sritharan P, Lin YC, Pandy MG. Muscles that do not cross the knee contribute to the knee adduction moment and tibiofemoral compartment loading during gait. Journal of orthopaedic research : official publication of the Orthopaedic Research Society. 2012;30(10):1586-95.

162. Sritharan P, Lin YC, Richardson SE, Crossley KM, Birmingham TB, Pandy MG. Lower-limb muscle function during gait in varus mal-aligned osteoarthritis patients. Journal of orthopaedic research : official publication of the Orthopaedic Research Society. 2018. 163. Costa RA, Oliveira LM, Watanabe SH, Jones A, Natour J. Isokinetic assessment of the hip muscles in patients with osteoarthritis of the knee. Clinics (Sao Paulo, Brazil). 2010;65(12):1253-9.

164. Holla JF, Sanchez-Ramirez DC, van der Leeden M, Ket JC, Roorda LD, Lems WF, et al. The avoidance model in knee and hip osteoarthritis: a systematic review of the evidence. Journal of behavioral medicine. 2014;37(6):1226-41.

165. Delp SL, Hess WE, Hungerford DS, Jones LC. Variation of rotation moment arms with hip flexion. JBiomech. 1999;32(5):493-501.

166. Neumann DA. Kinesiology of the Musculoskeletal System - E-Book : Foundations for Rehabilitation2016.

167. Lloyd DG, Buchanan TS, Besier TF. Neuromuscular biomechanical modeling to understand knee ligament loading. Medicine and science in sports and exercise. 2005;37(11):1939-47.

168. Bernstein N. The co-ordination and regulation of movements. Oxford: Pergamon press; 1967.

169. Mobasheri A, Batt M. An update on the pathophysiology of osteoarthritis. Annals of physical and rehabilitation medicine. 2016;59(5-6):333-9. 
170. Ashok C. Effects of hip abductor muscle strengthening exercises in patients with osteoarthritic knee joints. Indian Journal of Physiotherapy \& Occupational Therapy. 2012;6:32-7.

171. Piercy KL, Troiano RP, Ballard RM, Carlson SA, Fulton JE, Galuska DA, et al. The Physical Activity Guidelines for Americans. Jama. 2018;320(19):2020-8.

172. Crossley KM, van Middelkoop M, Barton CJ, Culvenor AG. Rethinking patellofemoral pain: Prevention, management and long-term consequences. Best practice \& research Clinical rheumatology. 2019;33(1):48-65.

173. Caneiro JP, O'Sullivan PB, Roos EM, Smith AJ, Choong P, Dowsey M, et al. Three steps to changing the narrative about knee osteoarthritis care: a call to action. British journal of sports medicine. 2020;54(5):256-8.

174. Pua YH, Wrigley TV, Cowan SM, Bennell KL. Intrarater test-retest reliability of hip range of motion and hip muscle strength measurements in persons with hip osteoarthritis. ArchPhysMedRehabil. 2008;89(6):1146-54.

175. Skou ST, Simonsen O, Rasmussen S. Examination of muscle strength and pressure pain thresholds in knee osteoarthritis: test-retest reliability and agreement. Journal of geriatric physical therapy (2001). 2015;38(3):141-7.

176. Khanna D, Krishnan E, Dewitt EM, Khanna PP, Spiegel B, Hays RD. The future of measuring patient-reported outcomes in rheumatology: Patient-Reported Outcomes Measurement Information System (PROMIS). Arthritis care \& research. 2011;63 Suppl 11:S486-90.

177. Briani RV, Ferreira AS, Pazzinatto MF, Pappas E, De Oliveira Silva D, Azevedo FM. What interventions can improve quality of life or psychosocial factors of individuals with knee osteoarthritis? A systematic review with meta-analysis of primary outcomes from randomised controlled trials. British journal of sports medicine. 2018.

178. Broderick JE, Keefe FJ, Bruckenthal P, Junghaenel DU, Schneider S, Schwartz JE, et al. Nurse practitioners can effectively deliver pain coping skills training to osteoarthritis patients with chronic pain: A randomized, controlled trial. Pain. 2014;155(9):1743-54. 179. O'Moore K A, Newby JM, Andrews G, Hunter DJ, Bennell K, Smith J, et al. Internet Cognitive-Behavioral Therapy for Depression in Older Adults With Knee Osteoarthritis: A Randomized Controlled Trial. Arthritis care \& research. 2018;70(1):61-70. 180. O'Sullivan PB, Caneiro JP, O'Keeffe M, Smith A, Dankaerts W, Fersum K, et al. Cognitive Functional Therapy: An Integrated Behavioral Approach for the Targeted Management of Disabling Low Back Pain. Phys Ther. 2018;98(5):408-23.

181. White DK, Keysor JJ, Lavalley MP, Lewis CE, Torner JC, Nevitt MC, et al. Clinically important improvement in function is common in people with or at high risk of knee OA: the MOST study. The Journal of rheumatology. 2010;37(6):1244-51.

182. Pouli N, Das Nair R, Lincoln NB, Walsh D. The experience of living with knee osteoarthritis: exploring illness and treatment beliefs through thematic analysis. Disability and rehabilitation. 2014;36(7):600-7.

183. Goh SL, Persson MSM, Stocks J, Hou Y, Welton NJ, Lin J, et al. Relative Efficacy of Different Exercises for Pain, Function, Performance and Quality of Life in Knee and Hip Osteoarthritis: Systematic Review and Network Meta-Analysis. Sports medicine (Auckland, NZ). 2019;49(5):743-61.

184. @ewa_roos. Keeping physically active is important for good health. Here is some advice on how to exercise safely with painful knee joints. 2020.

185. Malliaras P, Cook J, Purdam C, Rio E. Patellar Tendinopathy: Clinical Diagnosis, Load Management, and Advice for Challenging Case Presentations. The Journal of orthopaedic and sports physical therapy. 2015;45(11):887-98. 
1575 186. Silbernagel KG, Thomee R, Eriksson BI, Karlsson J. Continued sports activity, using a

1576 pain-monitoring model, during rehabilitation in patients with Achilles tendinopathy: a

1577 randomized controlled study. AmJ Sports Med. 2007;35(6):897-906.

1578 187. Creamer P, Hochberg MC. Why does osteoarthritis of the knee hurt--sometimes? Br J

1579 Rheumatol. 1997;36(7):726-8.

1580 188. Bedson J, Croft PR. The discordance between clinical and radiographic knee

1581 osteoarthritis: a systematic search and summary of the literature. BMC musculoskeletal

1582 disorders. 2008;9:116.

1583 189. Baert IA, Staes F, Truijen S, Mahmoudian A, Noppe N, Vanderschueren G, et al.

1584 Weak associations between structural changes on MRI and symptoms, function and muscle

1585 strength in relation to knee osteoarthritis. Knee surgery, sports traumatology, arthroscopy :

1586 official journal of the ESSKA. 2014;22(9):2013-25.

1587 190. Bricca A, Juhl CB, Steultjens M, Wirth W, Roos EM. Impact of exercise on articular 1588 cartilage in people at risk of, or with established, knee osteoarthritis: a systematic review of

1589 randomised controlled trials. British journal of sports medicine. 2019;53(15):940-7.

1590 191. (NICE) NIfHaCE. Osteoarthritis: care and management [Online]. 2014 [updated

1591 February 2014. Available from: http://www.nice.org.uk/guidance/cg177/chapter/1-

1592 recommendations.

1593 192. Berenbaum F, Wallace IJ, Lieberman DE, Felson DT. Modern-day environmental

1594 factors in the pathogenesis of osteoarthritis. Nature reviews Rheumatology. 2018;14(11):674-

159581.

1596 193. Varbakken K. Exploring ICF's Body Function, Activities, and Participation in Knee

1597 Osteoarthritis (KOA) -discrimination on measures across WHO's International Classification

1598 of Function, Disability, and Health (ICF) and a ICF-biopsychosocial model predicting

1599 potential self-reported activities of daily life function for patients with knee osteoarthritis

1600 [PhD thesis]. To be published in NTNU Open: The Norwegian University of Science and

1601 Technology (NTNU); 2021.

1602 194. Sackett DL, Haynes RB. The architecture of diagnostic research. Bmj.

1603 2002;324(7336):539-41.

1604

1605

1606 
1608 
1610

1611 
1613

1614

1615

1616 


\section{Figures}

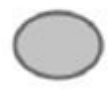

Body-mind exercises

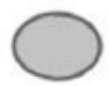

Strength exercises

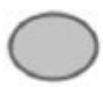

Endurance exercises

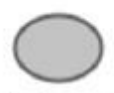

Activity level vigorous intensity

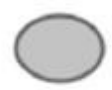

Assistive activity technology

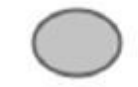

General health

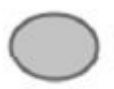

BMI

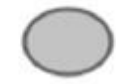

Medicine

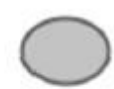

Diet

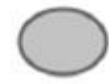

Sleep

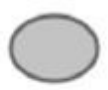

Rest

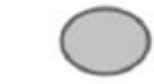

Quality-of-life view

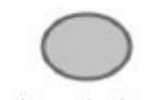

Knowledge

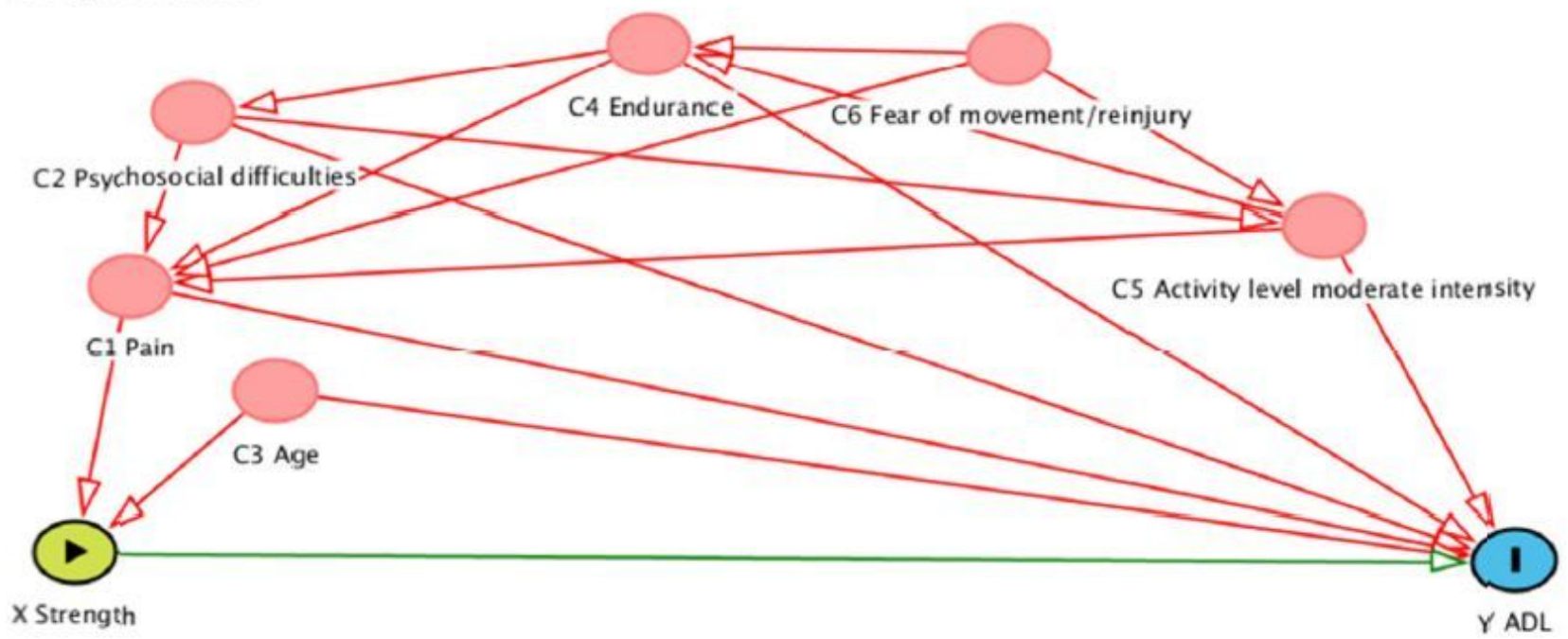

\section{Figure 1}

Modeling the total effect (green arrow) of the assumed focal predictor Strength (green play-button) on the putative outcome Activity of daily life (blue stop-button), together with the potential confounders (pink buttons, $\mathrm{Cl}-\mathrm{C} 6$ ) with their putative confounding or causal effects on the focal predictor and outcome (pink arrows) to be adjusted for in the multiple regression model. The gray buttons were ruled out of the main model based on case vs control non-discriminative characteristics in prior studies $(1,2)$ and the inclusion criteria in the current study (C4 skeletal comorbidity).

\section{Supplementary Files}

This is a list of supplementary files associated with this preprint. Click to download.

- EappendixBMCKV25.11.2020kl1428VAN.pdf

- EappendixBMCKV24.11.kl0849.VAN.pdf 